\title{
FINAL REPORT: CONCEPTUAL DESIGN OF AN ELECTRON ACCELERATOR FOR BIO- SOLID WASTE TREATMENT
}

Fermi National Accelerator Laboratory

Kirk and Pine Street / P.O. Box 500 / Batavia, IL 60510

Managed by Fermi Research Alliance, LLC for the U.S. Department of Energy

Office of Science

DOE National Laboratory Announcement Number: LAB 16-1438

DOE / Office of Science Program Office: High Energy Physics

PAMS Pre-Proposal Tracking Number: PRE-0000008407

Research Track and Topic: 1.3 Accelerator R\&D Stewardship / Energy and Environmental Applications of Accelerators

September 20, 2017

Fermi National Accelerator Laboratory

Metropolitan Water Reclamation District of Chicago

FERMILAB-FN-1055-DI

This manuscript has been authored by Fermi Research Alliance, LLC under Contract No. DE-AC02-07CH11359 with the U.S. Department of Energy, Office of Science, Office of High Energy Physics. 


\section{Table of Contents}

1. INTRODUCTION 3

2. MWRD REQUIREMENTS 4

3. ACCELERATOR BASELINE CONCEPTUAL DESIGN $\quad 7$

4. ACCELERATOR SYSTEMS $\quad 11$

A. ACCelerator RF Design, Beam Dynamics, AND Thermionic Gun 12

B. FIELD EMISSION SOURCE (ALTERNATIVE) 16

C. MeChanical GUN Design INCLUDING GUN COUPLERS 19

D. RF CIRCUIT FOR RF GUN

E. POWER COUPLeR DESIGN

F. Cryostat Design

G. Thermal AND MAgnetic Shielding $\quad 22$

H. RF POWER SOURCE

l. NB ${ }_{3}$ SN Coated Cavities $\quad 25$

J. CONDUCTION COOLING 27

K. Accelerator Controls Needed for Reliable Turn-Key Operation 28

L. BEAM DIAGNOSTICS

M. BEAM DELIVERY SYSTEM $\quad 31$

N. RADIATION SHIELDING

5. R\&D NEEDED FOR KEY SYSTEMS AND TECHNOLOGIES $\quad 36$

6. DEVELOPMENT MILESTONES $\quad 38$

7. PARAMETRIC COST ESTIMATE

8. ESTIMATE OF OPERATIONS COSTS $\quad 41$

9. ESTIMATE OF ACCELERATOR RELIABILITY

10. SUMMARY / CLOSING REMARKS 


\section{Introduction}

Several studies $\left[{ }^{1}\right]\left[^{2}\right]\left[\left[^{3}\right]\left[{ }^{4}\right]\right.$ have identified electron beam (EB) irradiation of municipal wastewater and bio-solids as an effective and promising approach to the environmental remediation of the enormous quantities of human waste created by a growing world-wide population and increased urbanization. However, despite the technical success of experimental and pilot programs over the last several decades, the technique is still not in commercial use anywhere in the world. The recent DOE hosted "Workshop on Energy and Environmental Applications of Accelerators" identifies

"Several barriers exist to commercialization of electron beam technology for environmental applications. The first is the non-existence of commercial equipment that is configured for use in a high-volume drinking water, wastewater, or water reuse treatment plant. Second, the cost of an electron beam-based water or gas treatment system (capital plus operating expenses) is too high to be competitive with other technologies currently in use for most large-scale environmental applications. Third, the environmental "industry" is not familiar with electron beam technology, electron beam equipment, or radiation treatment in general. Fourth, for the technology to be used at a large scale (i.e., large market), high-power electron beam systems (>1 MW) will need to be developed."

In addition, the report also identifies the need for "Financial and infrastructure participation from a utility for demonstration project" and "Education and awareness of safety of utilizing electron beam technology" as two additional roadblocks preventing technology adoption of EB treatment for bio-solids.

In this concept design, we begin to address these barriers by working with Metropolitan Water Reclamation District of Greater Chicago (MWRD) and by the applying the latest accelerator technologies developed at Fermilab and within the DOE Office of Science laboratory complex. The MWRD is one of world's largest organizations processing municipal wastewater, with an annual budget authority exceeding $\$ 2$ billion, serving approximately 5 million people in 125 municipalities. The coverage area is 883 square

1. Hundal, L. S., K Kumar, A. Cox, H. Zhang, T. Granato. 2014. Improvements in biosolids quality resulting from the Clean Water Act. Water Environ. Res. 86:134-140.

2. Oladeji, O. O., G. Tian, A. E. Cox, T. C. Granato, C. O'Connor, A. Abedin, R. I.Pietz. 2013. Effect of long-term application of biosolids for mine land reclamation on groundwater chemistry: nutrients and other selected qualities. J. Environ. Qual. 42:94-102.

3. Oladeji, O. O., G. Tian, A. E. Cox, T. C. Granato, R. I. Pietz, C. R. Carlson, A. Abedin. 2013. Effect of long-term application of biosolids for mine land reclamation on groundwater chemistry: trace metals. J. Environ. Qual. 41:1445-1451.

4. Broadhurst, C. L., R. L Chaney, A. P. Davis, A. Cox, K. Kumar, R. D. Reeves, C. E. Green. 2014. Growth and cadmium phytoextraction by Swiss chard, maize, Rice, Noccaeacaerulescens, and Alyssum murale in pH adjusted biosolids amended soils. Int. J. Phytoremediation. 17:25-39. 
miles, incorporating over 550 miles of sewer mains. The Stickney Treatment Plant is the largest single waste treatment facility on earth, treating upwards of 1.2 billion gallons of water per day. MWRD provided the experience, research and development (R\&D) capability, organizational depth, and historical data to create realistic EB processing requirements and cost targets for the required EB accelerator systems.

Starting from real world requirements provided by MWRD, Fermi National Accelerator Laboratory (Fermilab) and its university and industrial partners have created a concept accelerator design that leverages our extensive experience in design and construction of high-power, high-reliability accelerators for high energy physics. The team's practical experience with production cost estimates for accelerator components and systems and with large scale accelerator operations has allowed us to make credible estimates of both capital and operating costs as well as reliability for a high power industrial accelerator. Finally, our team's beam physics expertise and powerful simulation capability has allowed us to simulate in detail the performance of our accelerator concept demonstrating that, if built, it can perform as intended.

Colorado State University (CSU), Northern Illinois University (NIU) and industrial partners, Euclid TechLabs LLC (Euclid), Calabazas Creek Research, Inc. (CCR), and Communications and Power Industries (CPI) have all made key contributions to both the R\&D effort and to the writing of this report. This ensemble of partners was ideally positioned with both state-of-the-art knowledge and the practical experience necessary to create a cost effective industrial accelerator design suitable for EB treatment of wastewater and biosolids.

\section{MWRD Requirements}

The stewardship partner for this study is the Metropolitan Water Reclamation District of Greater Chicago (MWRD). MWRD initially identified five possible areas of interest in their existing treatment facilities where Electron Beam (EB) treatment may be feasible and cost attractive. Two of these treatment areas were examined in this study, as follows:

1. EB treatment of waste activated sludge (WAS).

2. Treatment of dewatered bio-solids to destroy organics and achieve the required volatile solids reduction required of Class A Sludge standard "exceptional quality bio-solids".

Figure 2.1 is a process flow schematic of part of the MWRD Stickney facility. The 2 million gallons per day (MGD) flow (5\% solids) under the block titled WAS thickening is the first area of focus. Treating this stream prior to the anaerobic digesters with $10 \mathrm{kGray}$ (actual value to be determined by experiment) would require a minimum of $0.9 \mathrm{MW}$ of electron beam power into the waste stream. The $71 \%$ efficiency of assuring $10 \mathrm{kGy}$ minimum dose on all treated material (see section $4 . \mathrm{m}$ ) raises the requirement on the EB power to $1.27 \mathrm{MW}$. This process flow clearly establishes the "industrial need" for a $1 \mathrm{MW}$ class industrial electron beam accelerator. Assuming $75 \%$ wall plug power efficiency, the 
required accelerator would consume 1.7 MW of electrical power.

The second area of focus, dewatered bio-solids, is not shown on the flow diagram. Dewatered bio-solids at MWRD Stickney is a waste stream that has been centrifuged to increase the fraction of solids vs water. Currently this process stream is either air dried in large open fields or immediately treated with heat. After processing, these bio-solids must have a sufficiently low Escherichia coli (E. coli) count to be classified as Class A waste if they are to be used as fertilizer for crops. This stream in the Stickney Plant is about $0.5 \mathrm{MGD}$ (of which $25 \%$ is solids). Treatment with a $10 \mathrm{kGy}$ dose would require a minimum of $0.27 \mathrm{MW}$ of e-beam power into the waste stream. The $71 \%$ efficiency of delivering this dose (see section 4.m) raises the requirement on the EB power to $380 \mathrm{~kW}$. Again, assuming overall $75 \%$ wall plug power efficiency the accelerator system would need $480 \mathrm{~kW}$ of electrical power in operation. We view this stream as the most likely "first target" for use of EB at the Stickney facility.

Schematic of MWRD Stickney WRP Treatment Process

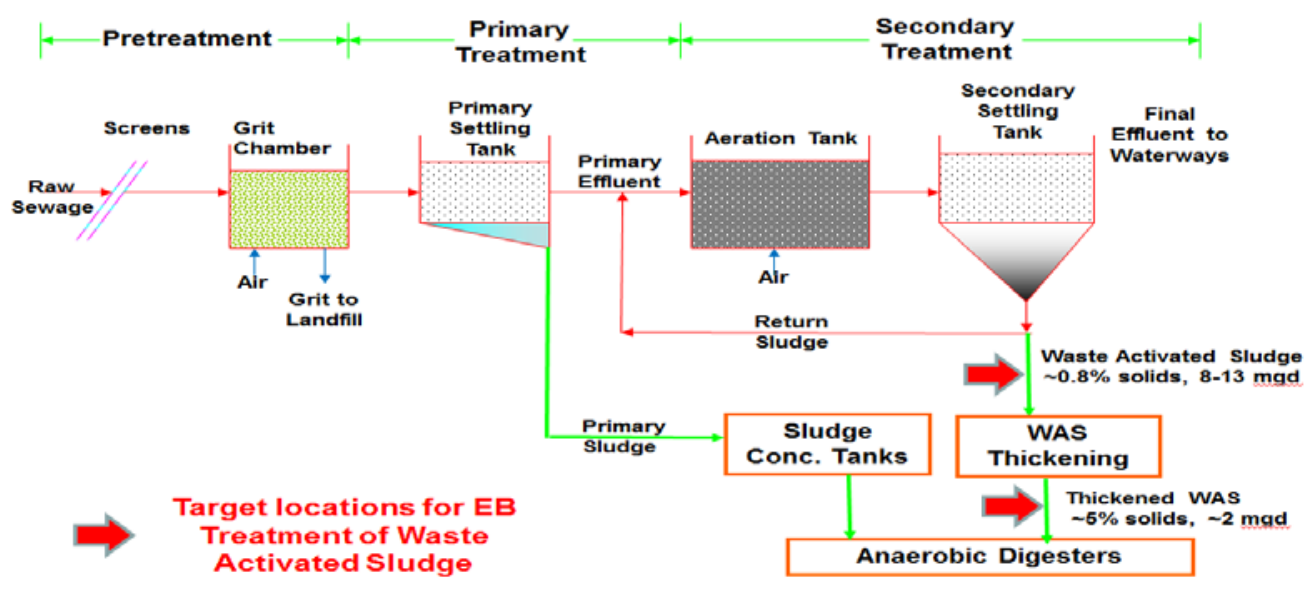

Figure 2.1: Process and flow Schematic the Chicago MWRD Stickney WRP Treatment Process. Red arrows indicate process locations where EB treatment of bio-solids may be of benefit. Bio-solids after the centrifuge are not shown in this figure but this flow is 0.5 MGD of which $25 \%$ is solids.

MWRD treats large volumes of waste on a continuous basis. For this reason, any accelerator system that becomes part of this treatment system is required to operate with very high reliability. Moreover, the accelerator must be optimized to be robust, and cost effective both in terms of capital and operating costs. 
Key requirements are:

- Acceptable capital cost for the entire system including the cost of shielded enclosures and beam delivery systems

- High overall wall plug power efficiency resulting in acceptable operating costs

- An optimized beam delivery process that minimizes the required EB power (due to the large volumes of materials to be processed)

- High reliability accelerator modules with redundancy to allow 24/7 availability

- A treatment process that meets all regulatory standards.

- Turn-key industrial solution that does not require expert operators

Also of importance to MWRD is the fact that treatment facilities already exist and new technology like an e-beam accelerator will likely need to be integrated into an existing facility. This means the accelerator and its shielded enclosure must be compact and yet have sufficient shielding to allow for people to work nearby while it is operating. In discussing requirements with MWRD it became clear that the method used to bring the electron beam into contact with the waste stream must guarantee that all the material receive the minimum required dose. Similarly, overall efficiency depends on achievable beam utilization and dose uniformity. Finally, introduction of EB processing must be done in a way that does not disturb overall plant operations or reliability. For treatment of the 2MGD process stream of water/bio-solids before anaerobic digestion, an efficient way must be found to apply the e-beam to material which is both located in a pipe and under pressure. This engineering problem is beyond the scope of this accelerator conceptual design study but is an area that requires future work.

Prior to submitting the proposal for this study, we evaluated various accelerator configurations to meet the requirements of a $1 \mathrm{MW}, 10 \mathrm{MeV}$ Type 3 accelerator as described in the Funding Opportunity Announcement (FOA) LAB 16-1438 using existing accelerators. Commercial electron accelerators exist that can be ganged to create $1 \mathrm{MW}$ of beam (e.g. the IBA Rhodotron T-1000 generates $560 \mathrm{~kW}$ at $7 \mathrm{MeV}$ ). However, in this case would take two such units to generate the required beam power and another unit to meet MWRD 24/7 reliability requirements. Moreover, their large physical size would require very large shielded enclosures. The net effect is that use of Rhodotrons would exceed the FOA Type 3 cost targets by a factor of 3 or more and these machines cannot meet the wall plug power efficiency target. Similarly, ILU accelerators developed by the Institute of Nuclear Physics are limited in beam power to $<100 \mathrm{~kW}$ and beam energy to $\sim 4 \mathrm{MeV}$ making them unattractive for processing large volumes of bulk solids where the higher beam energy is needed to penetrate the material and where many units would be required to generate the high beam power needed to process the large volume of materials. In addition, the wall plug power efficiencies of ILU accelerators are only about $30 \%$. None of the commercial accelerators today represent an effective, viable, turn-key solution for a 
waste water treatment facility.

Further considerations, such as overall EB power requirements, desire for high reliability, small accelerator physical size due to the cost of shielded enclosures, required wall plug power efficiency, and capital expense (CAPEX) cost/watt, led us to conclude that normal conducting accelerators are not well suited for MWRD wastewater and bio-solid applications. We considered high power Superconducting Radio-Frequency (SRF) linear electron beam (EB) accelerators based on cavities made of pure Niobium(Nb). Operation of such cavities at $2 \mathrm{~K}$ or below requires a sub atmospheric liquid Helium ( $\mathrm{LHe}$ ) refrigeration system which is both expensive and beyond that which industry would be willing to accept for an industrial accelerator. Similarly, $\mathrm{Nb}$ cavities operating at $4 \mathrm{~K}$ and at reasonable gradients (10 MV/M) have high cryogenic heat loads. Even if the accelerator is built with low frequency low gradient cavities (e.g. $325 \mathrm{MHz}$ ), the $4 \mathrm{~K}$ heat load for an industrial accelerator operating in continuous wave $(\mathrm{CW})$ mode is such that a large and complicated LHe plant is required. Moreover, the required cavities would be very large and expensive. While technically possible, such accelerators would be unattractive to industry and unlikely to meet FOA cost targets.

Examination of the MWRD process has led us to conclude that the relatively smaller process flows containing bio-solids in the two MWRD interest areas are the most attractive as a first target for EB treatment. The flow rates provided by MWRD for Waste Activated Sludge (WAS) of 2 Million Gallons per Day (MGD) and $10 \mathrm{kGy}$ dose lead to EB power requirements for the Stickney WRP that are well matched to $1 \mathrm{MW}$ class industrial EB accelerators, so we have used this as the baseline EB power requirement. The second area of interest, dewatered biosolids, has less stringent requirements.

Our accelerator concept is based on an industrial Superconducting Radio-Frequency (SRF) electron beam (EB) accelerator that leverages recent transformational SRF technology improvements $\left[{ }^{5}\right]$, especially the use of $\mathrm{Nb}_{3} \mathrm{Sn}$ coated cavities conduction cooled from commercial $4 \mathrm{~K}$ cryocoolers to achieve both reliability and cost targets via a modular approach. These cavities would be powered via an innovative low-cost RadioFrequency (RF) power source.

\section{Accelerator Baseline Conceptual Design}

We have developed a conceptual design of an Electron Beam (EB) accelerator module targeted at treatment of municipal wastewater and sludge that meets all requirements of a Type 3 Medium Scale, High Energy Accelerator as described in Table 1, page 7 of the DOE Accelerator Stewardship Funding Opportunity Announcement (FOA) LAB 16-1438.

5. R. Kephart et. al., "SRF, Compact Accelerators For Industry \& Society," FRBA03 Proceedings of SRF2015, Whistler, Ca (2015). 
We have evaluated the conceptual design against all issues outlined on page 8 of that same FOA and include that information in this report. The conceptual design of this accelerator and our rationale for that design is described below.

Accelerators for industrial applications are required to be both cost effective and reliable. One highly effective approach to reliability is via use of redundant units such that a spare can be brought on line quickly in the event of a failure. However, for mega-watt class accelerators, supplying $100 \%$ spare capacity is not cost effective. Thus, we have chosen an approach in which the full capacity of the accelerator is provided by multiple, fully independent modules. For SRF based accelerators, FOA cost targets are difficult to meet using solutions based on a large number modules (e.g. more than 6) due to the fixed cost per accelerator module of the SRF cavity, gun, cryostat, controls, and cryogenic refrigerator. We have concluded that a cost effective overall solution is 4 operating modules with one spare corresponding to an extra $25 \%$ of CAPEX spending to provide the needed redundant capacity.

We reexamined the choice of frequency, accelerating gradient, operating temperature and beam current. During this exercise, we validated our previous choice of a $41 / 2$ cell, $650-\mathrm{MHz}$, elliptical Niobium $(\mathrm{Nb})$ cavity with integrated electron gun, coated inside with $\mathrm{Nb}_{3} \mathrm{Sn}$, operated at $4 \mathrm{~K}$, and powered by an RF source with $80 \%$ efficiency or more and with an RF system target cost of $<\$ 2.5 / \mathrm{W}$. Each independent module operates at an average current of $25 \mathrm{~mA}$ and is designed to deliver $250 \mathrm{~kW}$ of $\sim 10 \mathrm{MeV}$ electrons in Continuous Wave (CW) operation. Only 4 of 5 accelerator modules need to provide beam to meet the $1 \mathrm{MW}$ objective providing the redundancy required by our stewardship partner MWRD for 24/7 operations. The spare unit would be kept at cryogenic operating temperatures so it could be turned on very quickly when needed. Elliptical SRF cavities at $650 \mathrm{MHz}$ is a natural choice for this application since it is a frequency already chosen for the Office of Science PIP-II project and extensive development work has already taken place. This frequency also represents a reasonable balance between the cavity physical size (i.e., installed cavity cost) and energy efficiency (operating cost) due to cavity cryogenic losses that increase with frequency. This choice also offers large cavity apertures for low beam losses. A significant design and simulation effort was carried out to examine the key issue of beam losses on cold cavity surfaces in a 250-kW unit which must be $<10^{-5}$ to limit cryogenic heat loads to acceptable values. Our simulations indicate beam losses of $<10^{-6}$ are achievable.

We estimate that an optimized, magnetically shielded, high quality factor (Q0), 650 $\mathrm{MHz}, \mathrm{Nb}_{3} \mathrm{Sn}$ coated, $4 \frac{1}{2}$ cell elliptical cavity can achieve dynamic RF losses $<2.5 \mathrm{~W}$ at $4.5 \mathrm{~K}$ when operated $\mathrm{CW}$, making development of such cavities with integrated SRF guns a high priority. An $\mathrm{e}^{-}$source that does not damage the cavity inner surface (i.e. the cavity $Q_{0}$ ) is also a key developmental task. Our preliminary investigations lead to an expected $4.5 \mathrm{~K}$ static heat leak of $0.75 \mathrm{~W}$ from a low loss cryostat; $0.2 \mathrm{~W}$ from the e- source; and 
$0.74 \mathrm{~W}$ from the ultra-low heat leak fundamental power coupler. Our target is a loss of < $0.5 \times 10-6$ of the beam corresponds to $<1.25 \mathrm{~W}$ at $4.5 \mathrm{~K}$. Achieving these targets means that an entire $250 \mathrm{KW}$ accelerator module can be cooled with less than $6 \mathrm{~W}$ of refrigeration at $4 \mathrm{~K}$. Such a load can be accommodated using several high-reliability commercial cryocoolers and by using conduction cooling. Cryocoolers with $2.5 \mathrm{~W}$ capacity are available today (e.g. CryoMech) and several companies are actively developing higher capacity units such that we anticipate that only one or two such cryocoolers will be needed for each module. Use of conduction cooling and $4 \mathrm{~K}$ cryocoolers makes possible a simple cryostat that contains no liquid helium (Fermilab patents pending). This technique will lead to dramatic simplifications enabling a turn-key industrial SRF accelerator. Table 3.1 summarizes the anticipated $4 \mathrm{~K}$ heat load for a $250-\mathrm{kW}$ module.

\section{Heat Source}

Heat load to

Cavity RF losses

Low loss cryostat (static)

Low loss RF coupler

Thermionic electron source

Beam losses
4K (Watts)

$<2.5$

0.75

0.74

0.20

$<1.25$

$<5.50$ Watts

Table 3.1: Anticipated $4 \mathrm{~K}$ load sources for a $250 \mathrm{~kW}$ SRF accelerator module

FOA cost targets are very difficult to achieve using RF sources in current use for accelerators since such sources (e.g. klystrons, IOTs, Solid-state) typically have installed costs in the range \$5-15/Watt range. At \$ 10 per Watt, the RF source would consume the entire FOA target cost. Moreover, the wall plug power efficiency for a low heat leak SRF accelerator such as we propose is dominated by the efficiency of the RF power source. Therefore, we have adopted a solution based on an injection locked magnetron with integrated driver. Although magnetrons were developed pre-World War II for radar applications, they remain today, the most efficient and lowest cost source for the generation of RF power in the hundreds of $\mathrm{MHz}$ to few $\mathrm{GHz}$ frequency range. Millions of magnetrons are produced annually for kitchen microwave ovens at $2.45 \mathrm{GHz}$ where a 1$\mathrm{kW}$ magnetron has a cost less than a penny per Watt. Industrial RF heating systems employ $915 \mathrm{MHz}$ magnetrons operating at power levels exceeding $100 \mathrm{~kW}$ of CW RF output and achieve high reliability. The cost of such turnkey industrial heating systems is on the order of $\$ 1$ per watt of output RF power. The magnetron RF source we envision will be dynamically locked to the cavity resonant frequency eliminating the need for a cavity tuner, and the supply will be capable of $280 \mathrm{~kW}$ to allow sufficient overhead for control and regulation.

Driving an SRF-cavity based accelerator has more stringent requirements than simply providing heat for industrial processes. The RF source will require more complex controls 
and better spectral purity of the RF output. Fermilab recently applied for a patent for phase modulating an injection-locked magnetron, allowing for full vector modulation of the magnetron output. Peer reviewed papers $\left[{ }^{6}\right]\left[{ }^{7}\right]$ containing the details of these techniques are available. More importantly, this work gives us confidence that the approach of using low cost magnetrons will work for the industrial accelerator we propose. A target cost below $\$ 2.5$ per watt appears to be achievable for an optimized system in quantity production. Existing magnetron systems demonstrate wall plug power efficiencies approaching $80 \%$, a key requirement to meet Type 3 accelerator goals. We estimate that the overall wall plug power efficiency for the proposed accelerator system can be near $75 \%$, meeting not only Type 3 but also type 4 efficiency objectives. Figure 3.2 shows schematically what a first article $41 / 2$ cell accelerating structure might look like in a test cryostat.

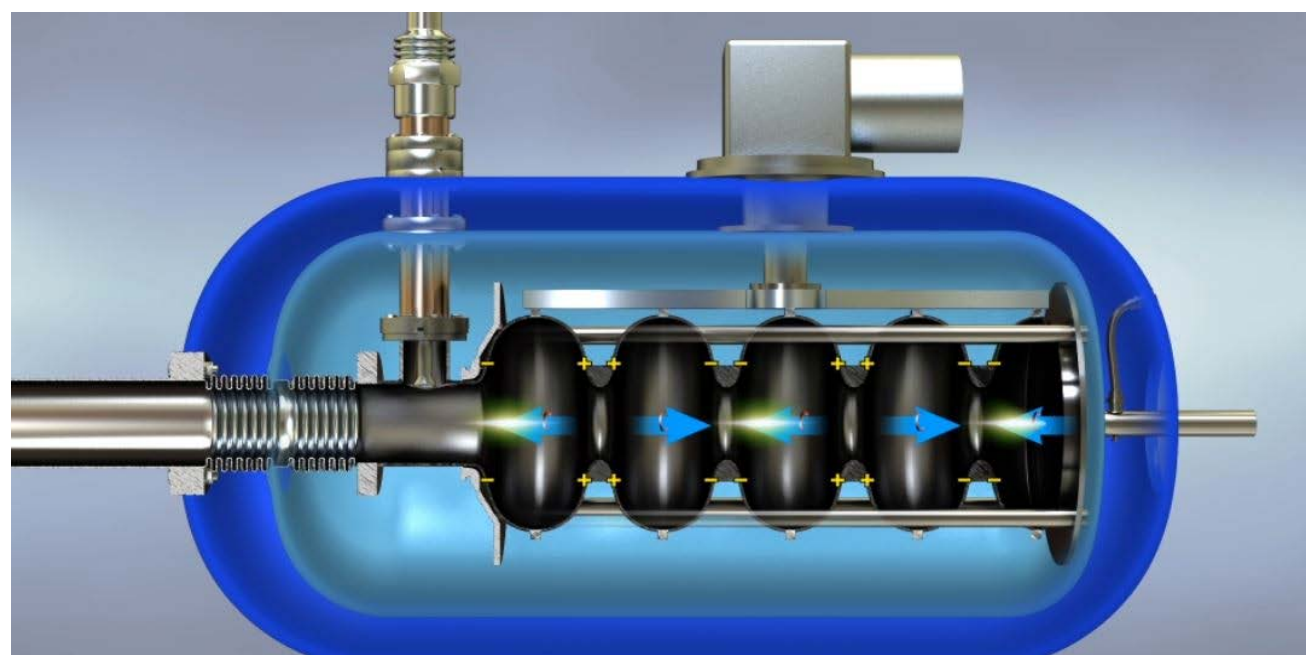

Figure 3.1. Schematic of a $250 \mathrm{~kW}, 650 \mathrm{MHz}, 41 \frac{1}{2}$ cell $650 \mathrm{MHz}$ SRF accelerator module with cryocooler cold finger in contact with the cavity. This is assumed to be a non-optimized test device. For simplicity, the cavity magnetic shielding and beam delivery systems are not shown.

Figure 3.3 illustrates what a first article might look like for $250 \mathrm{~kW}$ accelerator test module if it were skid mounted. The boxes indicate the approximate sizes of the cryocooler compressor, the magnetron based RF power source, and controls rack. The test system envisioned would be suitable for transport to a slip stream test site at MWRD or elsewhere where it could be used to evaluate the efficacy of the proposed treatment of bio-solids with EB. We note that for this test accelerator we opted for simplicity and no attempt was made to minimize the physical size of the accelerator. We believe that in its final form the accelerator can be significantly more compact which can help to minimize

6. G. Kazakevich, R. Johnson, G. Flanagan, F. Marhauser, V. Yakovlev, B. Chase, V. Lebedev, S. Nagaitsev, R. Pasquinelli, N. Solyak, K. Quinn, D. Wolff, V. Pavlov, "High-power magnetron transmitter as an RF source for superconducting linear accelerators," Nuclear Instruments and Methods in Physics Research, A760 (2014), 19-27.

7. Precision vector control of a superconducting RF cavity driven by an injection locked magnetron. B. Chase, R. Pasquinelli, E. Cullerton, P. Varghese Journal of Instrumentation 11/2014; 10(03). DOI:10.1088/1748-0221/10/03/P03007 
radiation shielding costs and facility footprint, another key design feature required to achieve overall system FOA cost targets.

\section{Accelerator Systems}

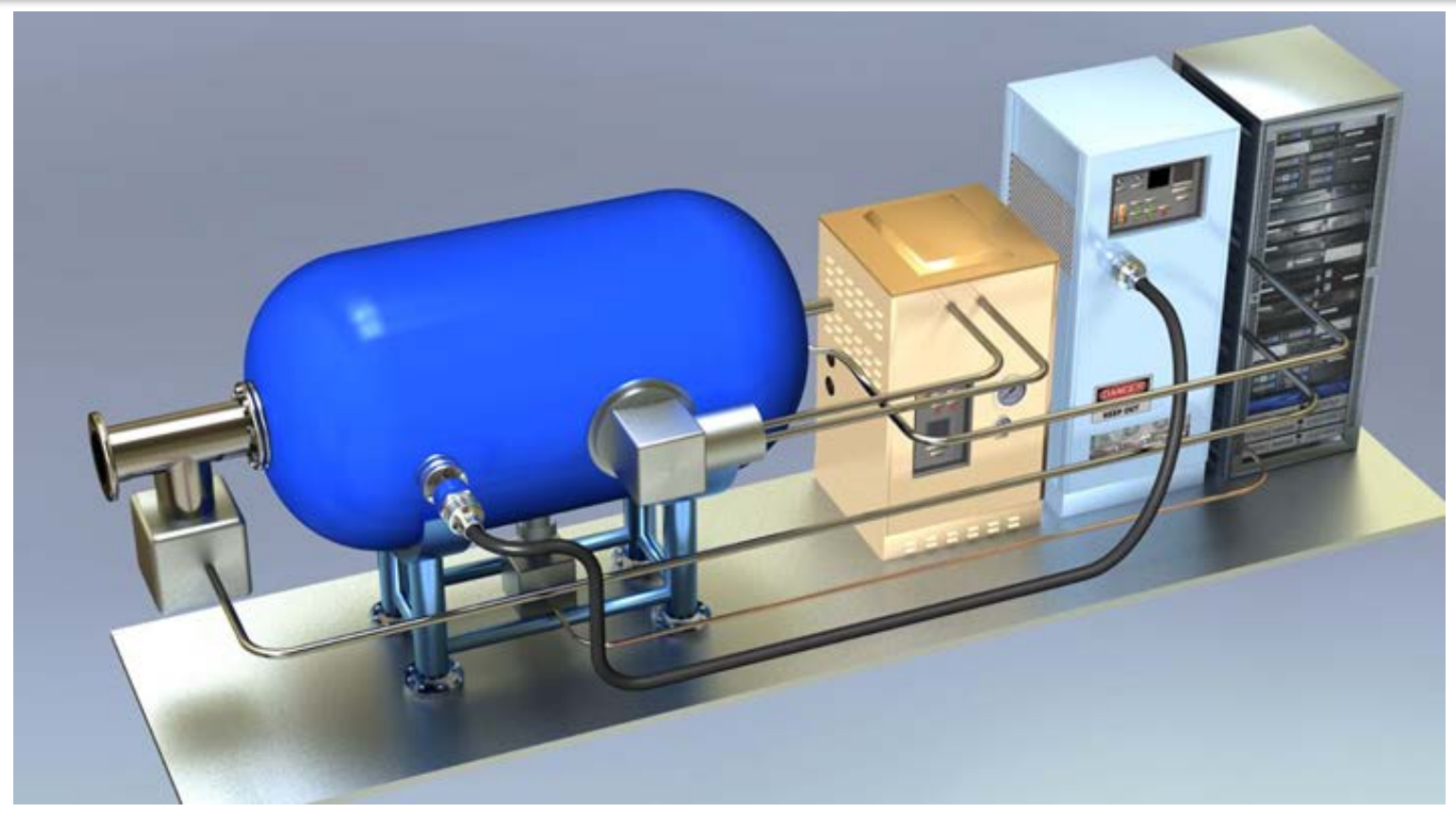

Figure 3.2 Rendering of a 250-kW accelerator test system skid mounted with controls, chiller and power supply. In production, vacuum vessel, RF Power source, controls rack, etc. can likely be substantially smaller.

Results reported in this section summarize the conceptual design of various accelerator systems and a full simulation of accelerator physics issues including simulation of the electron gun and beam loss to cold cavity surfaces. We also explored the technical and engineering feasibility of key components and systems. In section 5 we list key R\&D efforts needed to help develop these systems and technologies. Using this accelerator concept, we created a parametric cost estimate for an accelerator module. Although overall accelerator reliability depends on detailed engineering designs which were not funded by this study, we did examine various system approaches including tradeoffs like system redundancy vs component reliability and improved mean-time-to-failure vs improved mean-time-to-repair leading to estimates in later sections of uptime and required staff and costs for operations and maintenance. Similarly, required beam diagnostics, controls, and overall reliability for turn-key operations also depend on the detailed engineering design of the accelerator. Nevertheless, we examine instrumentation and control issues and made our best estimate of associated costs. 


\section{a. Accelerator RF Design, Beam Dynamics, and Thermionic Gun}

For our baseline concept, the electron gun is directly integrated into a $4 \frac{1}{2}-\mathrm{cell} 650 \mathrm{MHz}$ superconducting cavity. The first or "gun" cell is shorter (it is approximately a half cell so we use that term in the text below) while the remaining 4 cells are identical and use a cell shape scaled from a $1300 \mathrm{MHz} \beta=1$ elliptical cavity designed for the European $\mathrm{x}$-ray source (XFEL). We have simulated performance of gun cells of various lengths in the range of 0.3-0.8 of the length of a regular cell. Optimization of cavity parameters such as Epeak/Eacc and Bpeak/Eacc was done with COMSOL for various scale factors. Beam simulation used SMASON near the cathode and ASTRA for beam dynamics in the rest of the cavity. Our results show that the optimal scale for the gun cell is 0.7 .

A summary of main cavity parameters for the optimal scale 0.7 , electric and magnetic fields distribution are given in Figure 4a.1.

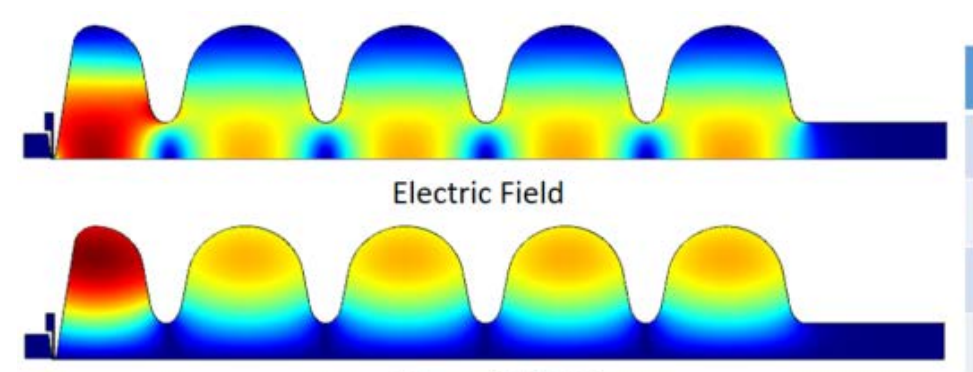

Magnetic Field

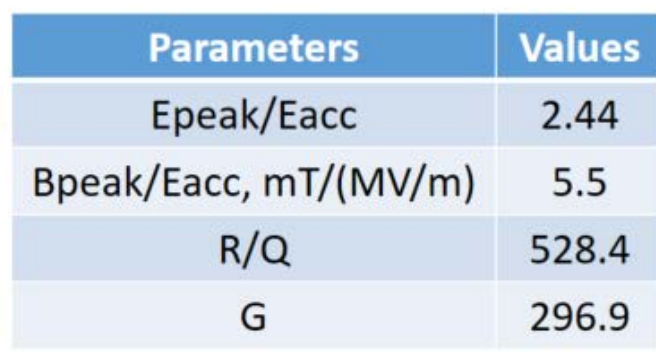

Figure 4a.1: The electric and magnetic fields distribution (left) and main cavity parameters (right).

The operation of a thermionic cathode directly inside a superconducting cavity presents new challenges. Efficient beam capture and acceleration requires bunches with small temporal duration and low energy spread. Challenging limits exist for beam loss to $4 \mathrm{~K}$ cavity surfaces (< few Watts) due to the choice of SRF technology and cooling method. Finally, cathode material migrating into the SRF cavity surface could lead to lower cavity $\mathrm{Q}_{0}$ and higher $4 \mathrm{~K}$ heat loads. (Note: If cavity surface contamination issues cannot be mitigated, the integrated gun could be replaced with a warm gun delivering electrons at about $10 \mathrm{keV}$ from a cathode located far from the SRF cavity surface. The result is a less compact but more conservative solution.)

The thermionic-emission process can be temporally shortened by using a second harmonic RF field. Simulations of shorter electron-bunch duration yields very low beam losses on the SRF cavity surface while providing electron-beam parameters with good duration and energy spread, comparable to the required values.

A miniature standard commercial thermionic cathode $(\varnothing=3.5 \mathrm{~mm})$ provides the needed beam currents while introducing very small heat loads. The proposed RF Gun with a 
tungsten dispenser thermionic cathode is intended to be cost-effective, simple, and have a long operating lifetime. Optimization of the RF phase of the gun RF with respect to the main cavity RF allows minimization of the output bunch's energy spread, duration, and beam losses during the acceleration in the SRF cavity.

A preliminary feasibility study of the beam dynamics of the RF-gun - accelerator system has been done. A combination of the 2-D SMASON program package and an ASTRA beam dynamics code were used to perform the simulations. SMASON was used to propagate the beam from the cathode to the iris region of the first accelerating cell. SMASON is capable of simultaneously simulating multiple RF frequencies and fields including DC fields and can track particles through these fields. It also includes space charge effects making it ideal for simulating the complexity near the cathode of our design. The ASTRA beam dynamics code is used beyond the iris of the first cell as the field complexity is greatly reduced and it runs much faster.

For every set of voltage parameters, the phase difference field in the RF Gun and the RF field in the cavity were optimized. The average beam current was adjusted to $25 \mathrm{~mA}$ by adjusting the voltage of the second harmonic RF field applied to the gap between the cathode and the cavity. To increase the current, the difference between the RF voltage and DC bias can also be increased. Geometric parameter optimization has been done in SMASON.

For optimized parameters of the gun, the results of SMASON simulations at the exit of the first accelerating cell (gun-cell) are summarized in several plots in Figure 4a.4. The RF gun produces a compact, but not Gaussian bunch with a tail in longitudinal phase space. The bunch at the gun exit has a RMS energy of $\sim 1.75 \mathrm{MeV}$ with a $\sim 60 \mathrm{keV}$ energy spread. Charge of each macroparticle in SMASON simulation is different and in Figure 4a.4 the color of each point represents the weight of charge from maximum value (red) to minimum value(blue). 

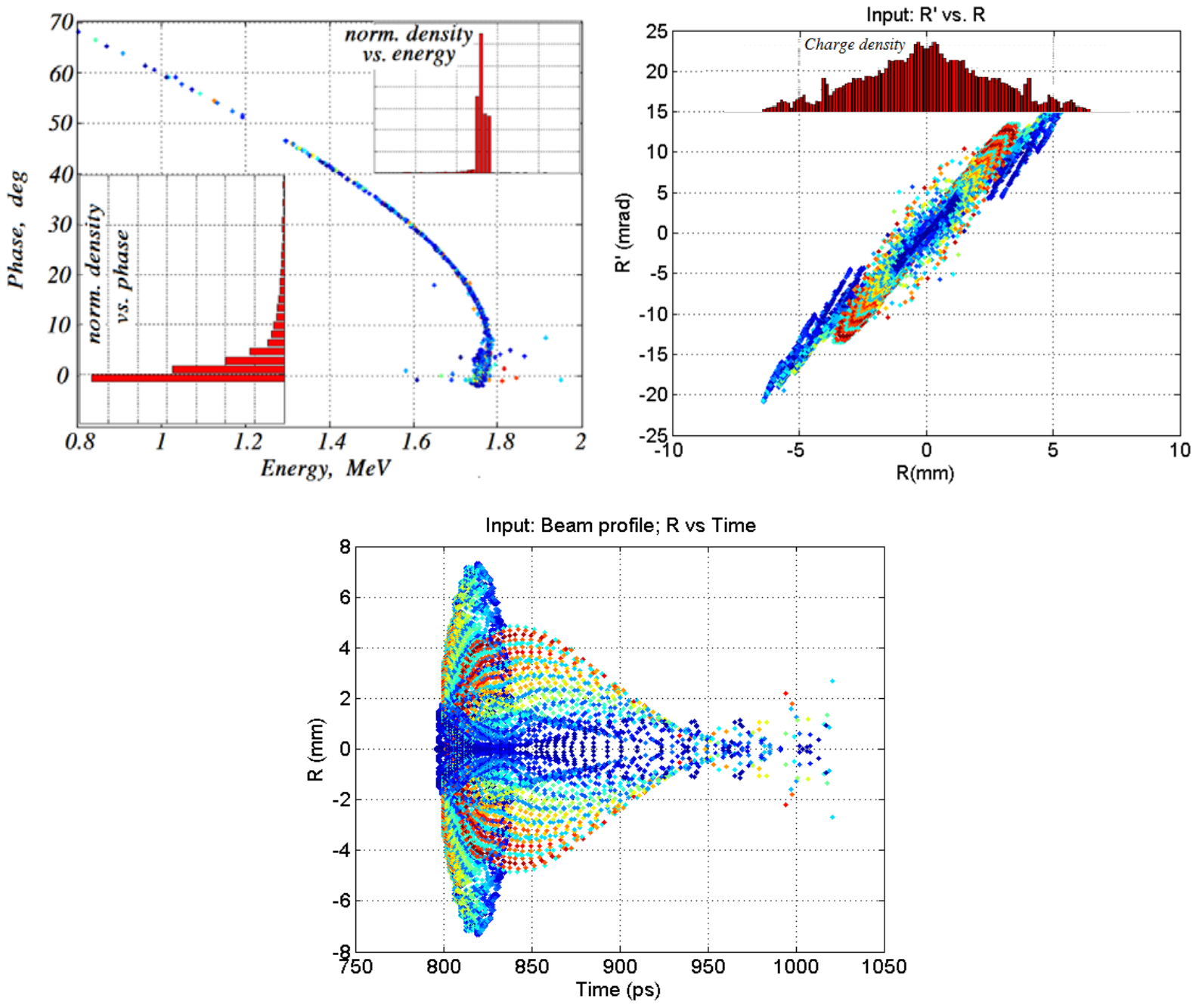

Figure 4a.4: Particle distribution after the gun-cell for optimized parameters and geometry. Color shows the weight of the particle in simulation. (Top-left) Phase-energy distribution: RMS energy spread $60.2 \mathrm{keV}$; RMS phase spread 7.6 degrees; (Top-right) $R^{\prime}-R$ phase-space distribution and radial charge distribution: RMS bunch sizes; $\sigma x=\sigma y=1.82 \mathrm{~mm}$; (bottom) Arrival time distribution: $R M S$ time spread $\sigma t=32.5 \mathrm{ps}$. 
The bunch distribution from the SMASON code was used as an input distribution for ASTRA simulation of beam acceleration in the scaled ILC accelerating cells. SMASON 2D particle distribution was rotated around the longitudinal axis to create 3D distribution for ASTRA tracking in a 3D field map with space charge. Results of ASTRA simulations at the cavity exit are presented in Figure 4a.5. The final bunch energy is $10 \mathrm{MeV}$. Longitudinal bunch distribution is almost "frozen" for relativistic bunches after the gun-cell.
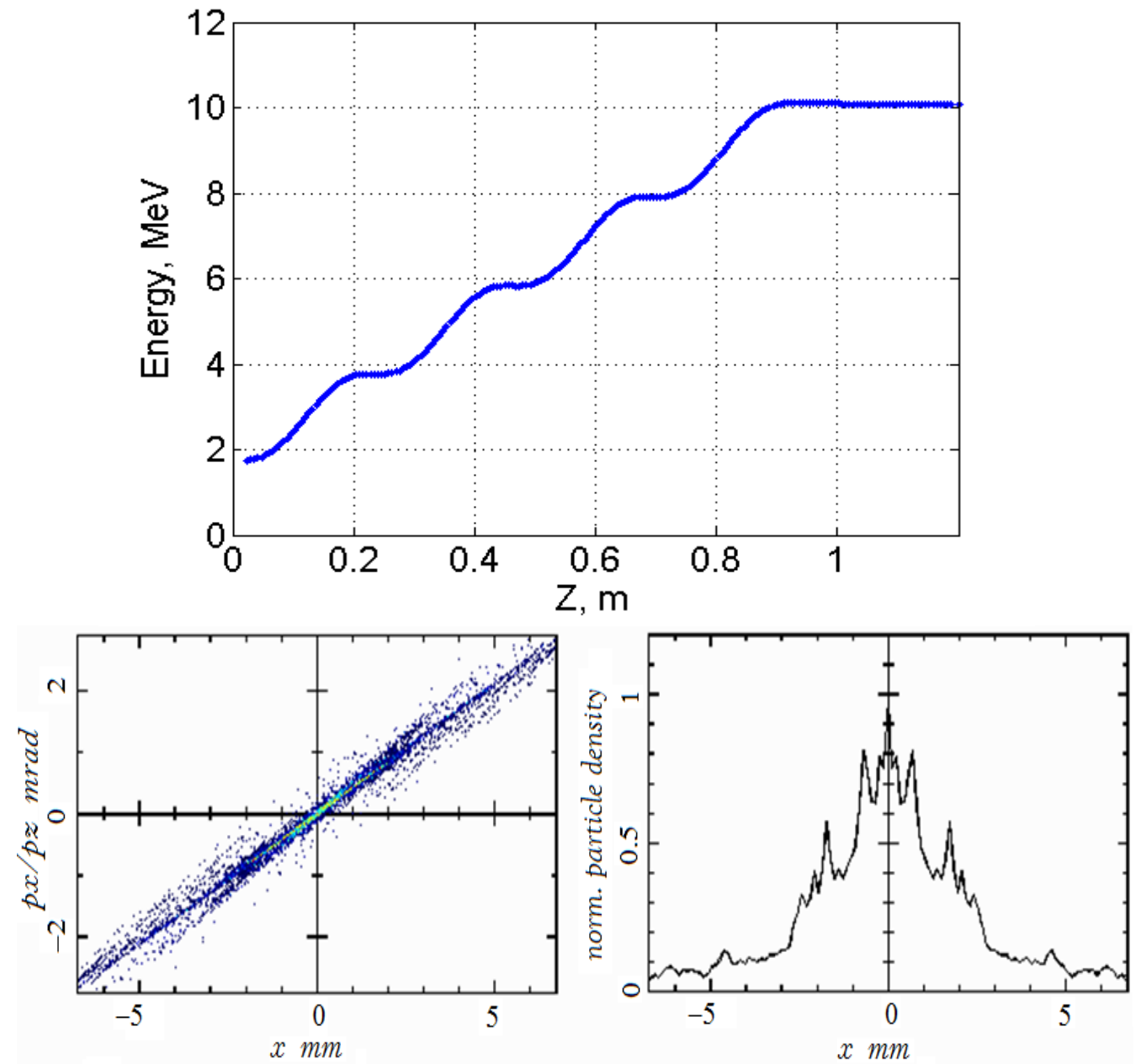

Figure 4a.5: (Top) Bunch acceleration along the cavity (RMS energy). (Middle Left) Transverse ( $\left.x-x^{\prime}\right)$ phasespace distribution. (Middle Right) Transverse beam charge density distribution.

In ASTRA simulations, we used up to 500k particles. No particle losses were indicated even in the presence of artificial apertures placed at half of the real cavity aperture. Because the tails of the distributions are important, more accurate simulations will be performed in further studies to verify absence of particle losses, using start-to-end simulations and cross-checking with other codes (MICHELLE, etc.). 


\section{b. Field Emission Source (alternative)}

In this section, we describe our studies of an alternative field emission electron-source option instead of our baseline of thermionic emission source. The goal was to determine if such sources could work and potentially be simpler and have longer operational lifetimes. The field emission of electrons from a surface occurs when the surface experiences a strong electric field. It is the macroscopic manifestation of quantum tunneling. Field emission for accelerator sources has gained interest over the last decade owing to new developments in field-emission displays and vacuum electronic devices. Additionally, field emission has also been extensively investigated as electron sources for bright $\left[{ }^{8}\right]$ or highcurrent electron beams. Advantages of field-emission over a thermionic source include the elimination of auxiliary systems, reduced operating temperature, and reduced cryogenic heat load. Also, since field emission occurs when the electric field pulls and then accelerates the electrons away from a surface, field emission is intrinsically gated by the applied electric field and therefore less prone to back bombardment from out-of-time electrons that reach the superconducting accelerating section than thermionic emission. Although not proven, these advantages could potentially make a FE source simpler, cheaper, and longer lived.

We studied a field emission cathode coupled to a $4 \frac{1}{2}$-cell SRF cavity. The RF field in the gap consists of the superposition of a fundamental $(f=650 \mathrm{MHz})$ and second harmonic $(f=1300 \mathrm{MHz}$ ) fields. To investigate the performance of a field-emission-based electron source we performed numerical simulation of the beam dynamics using the finitedifference time-domain (FDTD) program SPIFFE available from Argonne National Laboratory.

Figure $4 \mathrm{~b} .1$ displays the axial electric field at the cathode location for the first 3 ns (corresponding to 2 periods of the fundamental mode) along with the anticipated current density computed using the Fowler-Nordheim equation considering a field enhancement factor $\beta_{F E}=750$ and workfunction $\Phi=4.5 \mathrm{eV}$. These parameters are comparable to the case of a carbon-nanotube (CNT) cathode recently tested by our group $\left[{ }^{9}\right]\left[{ }^{10}\right]\left[\left[^{11}\right]\right.$. Based on the computed current density we anticipate a charge of $\sim 150 \mathrm{pC}$ per $650-\mathrm{MHz}$ RF bucket could be pulled from a cathode with radius of $3 \mathrm{~mm}$. This charge exceeds by a

8. P. Piot, C. A. Brau, B. K. Choi, B. Blomberg, W. E. Gabella, B. Ivanov, J. Jarvis, M. H. Mendenhall, D. Mihalcea, S. Panuganti, P. Prieto, J. Reid, Appl. Phys. Lett. 104, 263504 (2014).

9. J. D. Jarvis, H. L. Andrews, B. Ivanov, C. L. Stewar, N. de Jonge, E. C. Heeres, W.-P. Kang, Y.-M. Wong, J. L. Davidson, and C. A. Brau, J. Appl. Phys. 108, 094322 (2010).

10. M. Borland, Summary of Equations and Methods Used in spiffe, APS/IN/LINAC/92-2, 29 June 1992.

11. D. Mihalcea, L. Faillace, J. Hartzell, H. Panuganti, S. M. Boucher, A. Murokh, P. Piot, J. C. T. Thangaraj, Appl. Phys. Lett. 107, 033502 (2015). 
factor of 4 that necessary for a $10 \mathrm{MeV}, 250 \mathrm{~kW}$ module and indicates that beam powers approaching $1 \mathrm{MW}$ may be achievable with this method.

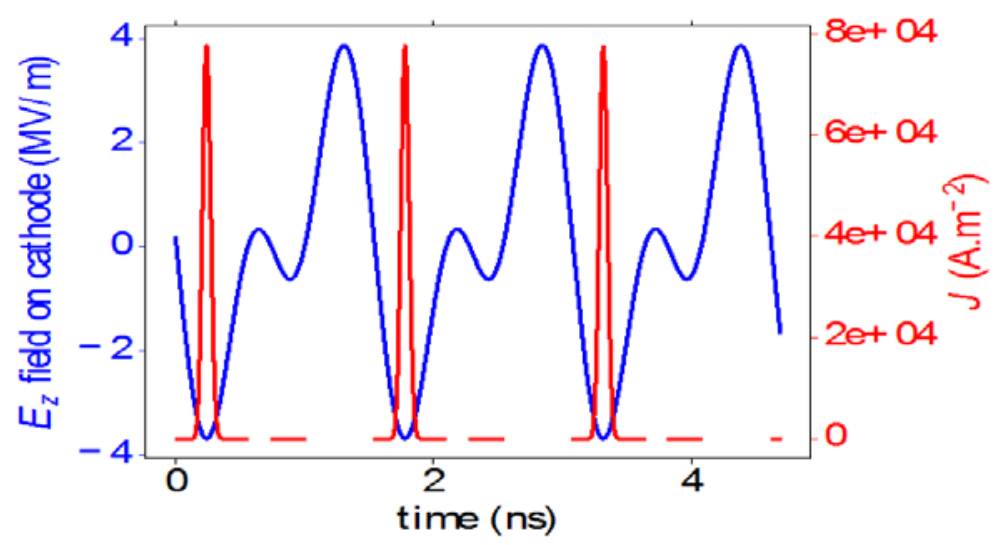

Figure 4b.1: Axial field applied on the cathode as a function of time (blue) with field-emitted current density (red-shaded trace).

Consequently, a circular cathode with radius $3-\mathrm{mm}$ was set up in the simulation and the phase of the SRF cavity was varied to explore the evolution of the beam parameters throughout the SRF cavity for distances up to 1.2-m downstream of the cathode. Figure $4 \mathrm{~b} .2$ presents the dependence of key target parameters as a function of $\phi_{\mathrm{SRF}}$ and confirms that a beam average momentum more than $10 \mathrm{MeV}$ can be attained with a fractional momentum spread below $5 \%$ (RMS). Lower values of $\phi_{\mathrm{SRF}}$ favor shorter bunch durations at the expense of energy decrease and fractional momentum spread increase. We select $\phi_{\mathrm{SRF}}=-18^{\circ}$ as a compromise between maximum energy, minimum fractional momentum spread while maintaining a bunch duration around $\sigma_{\mathrm{t}} \simeq 35 \mathrm{ps}$.

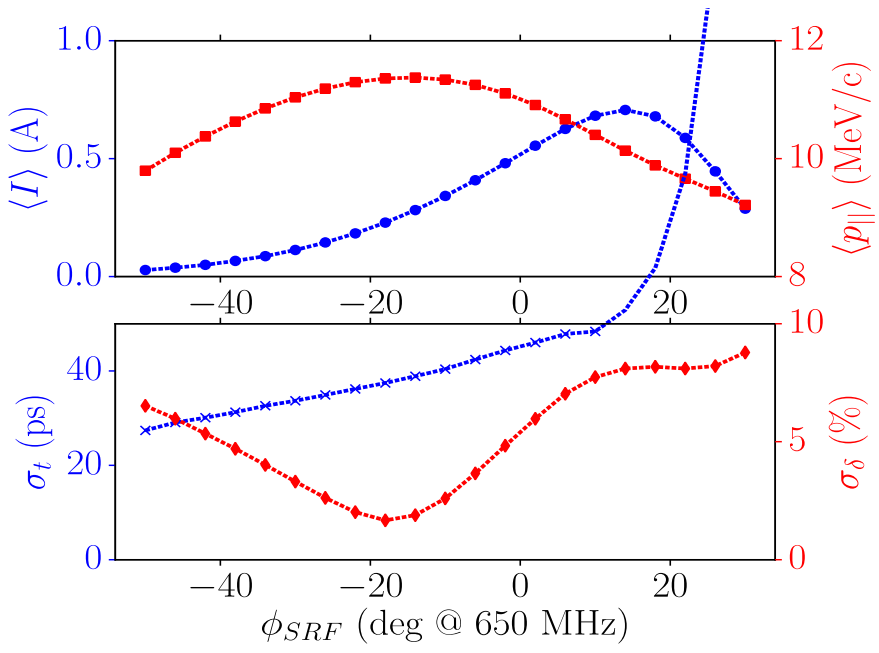

Figure 4b.2: Average current (blue) and beam energy (red) (top plot) and corresponding bunch duration (blue) and fractional momentum spread (red) (lower plot) as a function of the SRF-cavity phase.

The corresponding evolution of the longitudinal momentum and radial distributions during acceleration in the SRF cavity appear in Fig. $4 \mathrm{~b} .3$ along with associated RMS quantities for the case. For the selected phase $\left(\phi_{\mathrm{SRF}}=-18^{\circ}\right)$ we do not observe any backpropagating macroparticles and have no loss due to scraping on the cavity wall. The bunch duration reaches its final value after the second cell of the SRF cavity while the 
fractional energy spread continuously increases as the longitudinal-phase-space nonlinearity impressed by the RF waveform accumulates during the acceleration process.
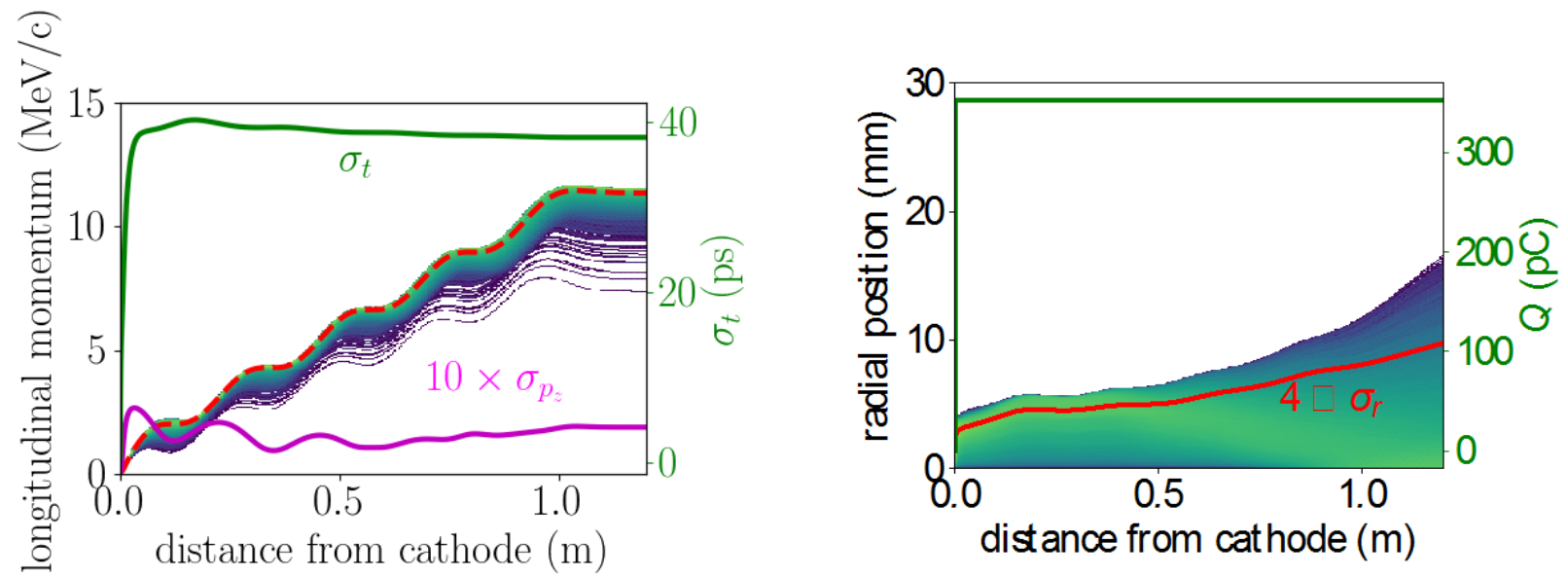

Figure 4b.3: Evolution of the longitudinal momentum (left) and radial (right) distribution along the SRF cavity (color density histograms). The green line on the left plot indicates the RMS bunch duration; the dash red line indicates the mean longitudinal momentum; the magenta line is 10 times the RMS momentum spread. The traces on the right plot respectively give 4 times the RMS radius (red) and the bunch charge (green).

The final longitudinal and transverse trace spaces simulated at $\mathrm{z}=1.2 \mathrm{~m}$ from the cathode are displayed in Figure 4b.4 The longitudinal phase space presents a significant quadratic correlation while the transverse phase space has the typical bow-tie shape with large-amplitude macroparticles being associated to lower energies.
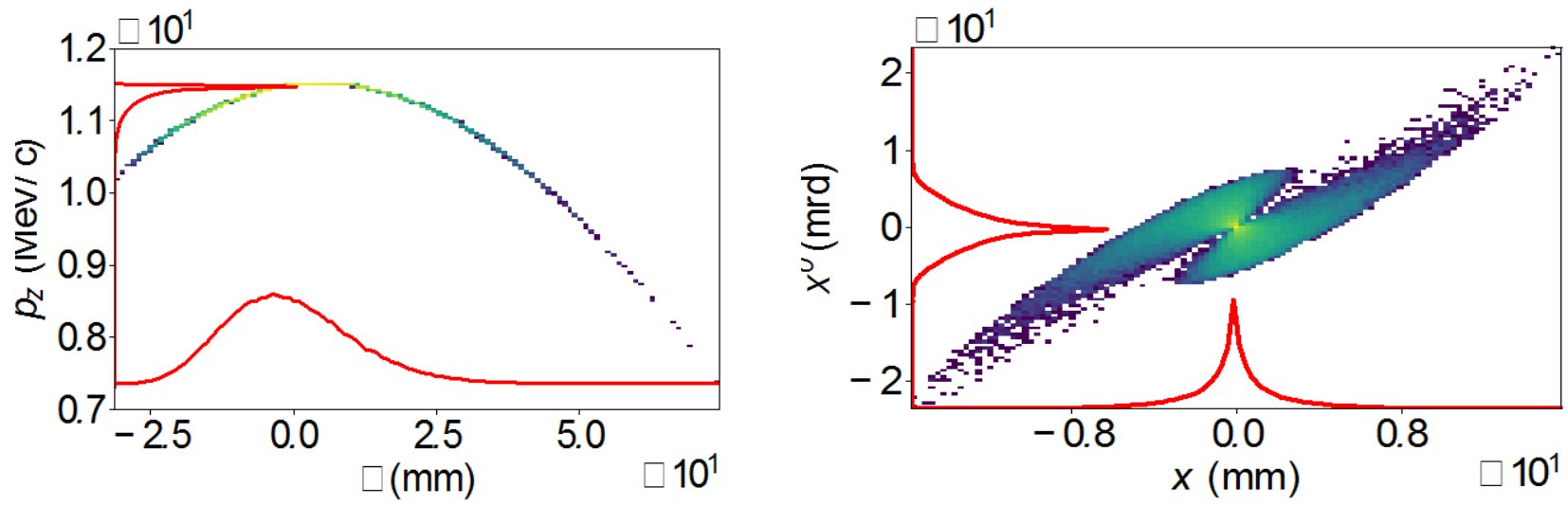

Figure 4b.4: Longitudinal (left) and transverse (right) trace-space distributions downstream of the SRF cavity (at $z=1.2 \mathrm{~m}$ from the cathode surface). The density plots are on a logarithmic scale. histograms). The traces on the left plot represent the RMS bunch duration (green), the mean longitudinal momentum (dash red) and 10 times the RMS momentum (magenta). The traces on the right plot respectively give 4 times the RMS radius (red) and the bunch charge (green).

In summary, the simulations presented suggest that the use of a field-emission source in the proposed setup could be a viable option as far as the beam dynamics is concerned. Further improvements of the modelling should include the precise optimization of the RF gap to produce the required field on the cathode (e.g. to possibly accommodate cathode 
materials with lower enhancement factors) and the investigation of the beam dynamics beyond the paraxial approximation used in the above simulations. Nevertheless, the study gives some impetus to further investigate the technological aspects associated with the inclusion of a field-emission source and especially identify cathode materials compatible with operation in the SRF cavity. Possible contenders, beside the CNT cathodes discussed earlier, include niobium nano-ribbons developed at Northern Illinois University [ $\left.{ }^{12}\right]$ or nanocrystalline planar cathodes from Euclid Lab. LLC [ $\left.{ }^{13}\right]$.

\section{c. Mechanical Gun Design Including Gun Couplers}

The mechanical design of the electron gun and its injection system is important for any RF linear electron accelerator. The optimal operating parameters of DC, RF voltage and phase interval for the gun were described in Section 4a. Experience has shown that for copper based accelerators, RF guns that use a thermionic cathode are cost effective, simple and reliable. They can be operated in various regimes without electron backward bombardment and can achieve small energy spread and beam losses during acceleration. Integrating such a gun into an SRF cavity presents new challenges. Beyond the HV standoff and RF requirements, there are additional requirements on thermal conduction and radiation as the gun components penetrate the SRF cavity insulating vacuum, thermal radiation shield, and magnetic shield. The gun design must also allow for differential motion of various gun and accelerator components during the cavity cool down.

The mechanical design concept of the RF gun for a 250-kW accelerator module is shown in Figure 4c.1. The cold part of the RF gun will be directly exposed to the ultraclean inside surface of the high Q SRF cavity. Thus, it is designed to UHV standards and will be cleaned and assembled mechanically with the thermionic cathode in a clean room before being attached to the cavity.

12. U. Patel, S. Avci, Z. L. Xiao, J. Hua, S. H. Yu, and Y. Ito, R. Divan and L. E. Ocola, C. Zheng, H. Claus, J. Hiller, U. Welp, D. J. Miller, and W. K. Kwok, Appl. Phys. Lett. 91, 162508 (2007).

13. S.V. Baryshev, S. Antipov, J. Shao, C. Jing, K. J. Pérez Quintero, J. Qui, W. Liu, W. Gai, A. D. Kanareykin, A. V. Sumant, Appl. Phys. Lett. 105, 203505 (2014). 


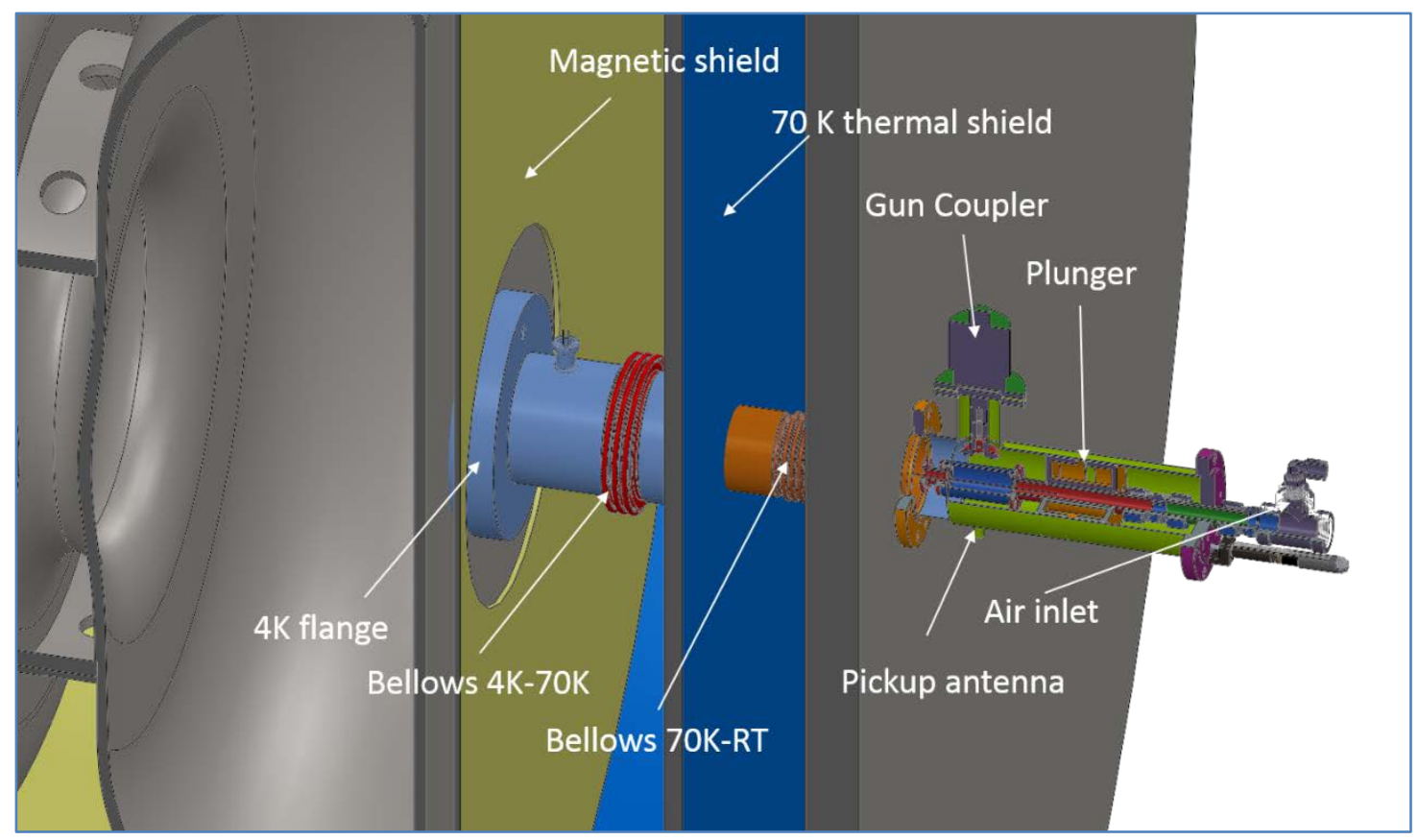

Figure 4c.1: Conceptual design for the RF-Gun

\section{d. RF Circuit for RF Gun}

For the baseline design, the RF gun needs to combine two harmonics. The first harmonic frequency is $650 \mathrm{MHz}$, corresponding to the operating frequency of the accelerating cavity. The second harmonic has a frequency of $1300 \mathrm{MHz}$. RF power of both harmonics is combined and supplied to the RF Gun.

The bandwidth of the $650 \mathrm{MHz}$ superconducting (SC) cavity is significantly narrower than the bandwidth of the normal conducting RF Gun. Therefore, the operating frequency of the SC cavity is a reference frequency for both harmonics of the RF Gun. To optimize beam parameters, amplitudes and phases of each harmonic are adjustable. This approach means that the accelerator cavity should be immune to most microphonic noise and, because the accelerator consists of a single cavity, it does not require that the cavity be equipped with a slow or fast tuner. This approach lowers the cost and simplifies the design.

The control box is based on digital programmable circuitry (FPGA) and an RF Transceiver (such as NI 5791R). The signal from the cavity field probe is read by the transceiver and converted into digital format. Converted signals are processed by the cavity resonant frequency stabilization algorithm running on FPGA (such us PXle-7972R). The signal driving the cavity will be split and pass though separate RF channels to the $650 \mathrm{MHz}$ RF Gun amplifier, and then through the up-converter to the $1300 \mathrm{MHz}$ RF Gun Amplifier. 


\section{e. Power Coupler Design}

As described earlier, we envision creating $1 \mathrm{MW}$ of beam power via $250 \mathrm{~kW}$ SRF-based accelerator modules. This approach can provide high reliability via redundancy and a stepwise growth path for industrial users. The cavities of these $250 \mathrm{~kW}$ modules will be cooled without liquid helium via conduction from a $4 \mathrm{~K}$ commercial cryo-cooler. Use of cryocoolers dramatically simplifies industrial SRF accelerators but requires that the overall cryogenic load at $4 \mathrm{~K}$ be modest. One significant contributor to the $4 \mathrm{~K}$ heat load is the main RF power coupler. Leveraging and extending previous work on a $1300 \mathrm{MHz}$ coupler, we succeeded in creating a concept for a $650 \mathrm{MHz}$ RF coupler that has an ultra-low cryogenic load of less than $1 \mathrm{~W}$ to $4 \mathrm{~K}$ when operated at $250 \mathrm{~kW}$ RF power.

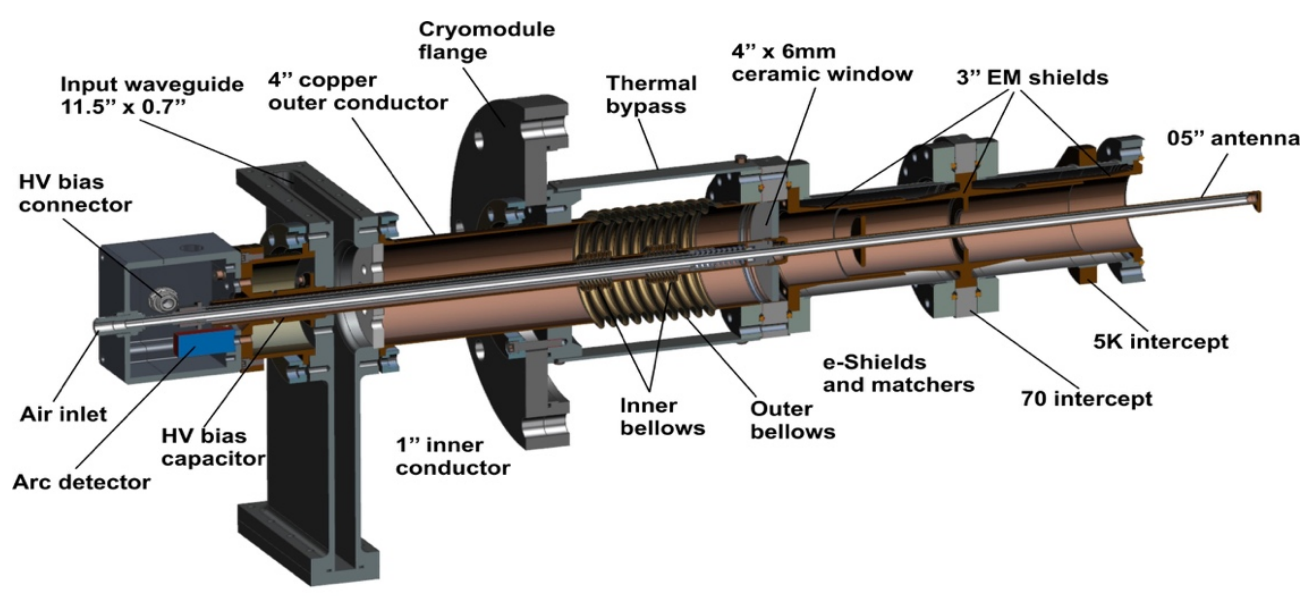

CAD concept for a $250 \mathrm{~kW}, 650 \mathrm{MHz}$, ultra-low loss RF power coupler

Our novel design is based on three electromagnetic copper screens that each are intercepted at higher temperatures to enable a low $4 \mathrm{~K}$ cryogenic load. Table 4e.1 below presents the estimated heat loads with no RF power applied, and at $250 \mathrm{~kW}$. The principle challenges are the very small gaps between copper shields. It will be important to begin construction of prototype couplers as soon as possible.

\begin{tabular}{|c|c|c|c|}
\hline Power, kW & Load at 4K, W & Load at 70K, W & Load at 293K, W \\
\hline 0 & 0.56 & 3.28 & -3.34 \\
\hline 250 & 0.74 & 7.40 & 12.9 \\
\hline
\end{tabular}

Table 4e.1: RF Power Coupler Static and dynamic heat loads. 


\section{f. Cryostat Design}

Our cryostat concept for an industrial accelerator with the cavity mounted horizontally is shown in Figure 4f.1. It consists of a vacuum vessel, thermal shield and magnetic shield encompassing a single $4 \frac{1}{2}$-cell $650 \mathrm{MHz}$ superconducting cavity. An electron gun as described above is integrated into the cryostat launching the electrons into the gun halfcell cavity. RF power is fed to the accelerator via an ultra-low loss coupler installed near the downstream of the cavity. The beam exits the accelerator through a thin low- $Z$ material vacuum window. The cryostat contains no liquid cryogens; rather, the cooling source for both the $80 \mathrm{~K}$ thermal shield and superconducting cavity is a set of cryocoolers. In figure 4f.1, we have assumed 3 W@4K GM cryocoolers will soon be available (e.g. CryoMech), so have shown two units that we believe will be sufficient to remove both the static heat load and the dynamic heat loads during operation. The number of cryocoolers could be larger or smaller depending on the achievable accelerator heat loads and available cryocooler $4 \mathrm{~K}$ capacities. Future work will include refinement of the cryostat design, design and simulation of thermal and magnetic shields; integration of the input power coupler; integration of multi-harmonic RF gun; design of cryocooler interfaces; and the development of a complete thermal model to allow simulation of the conduction cooling scheme using measured cavity heat loads, and cryocooler performance. We also plan to also explore a vertical cavity orientation that may reduce shielding requirements for some applications.

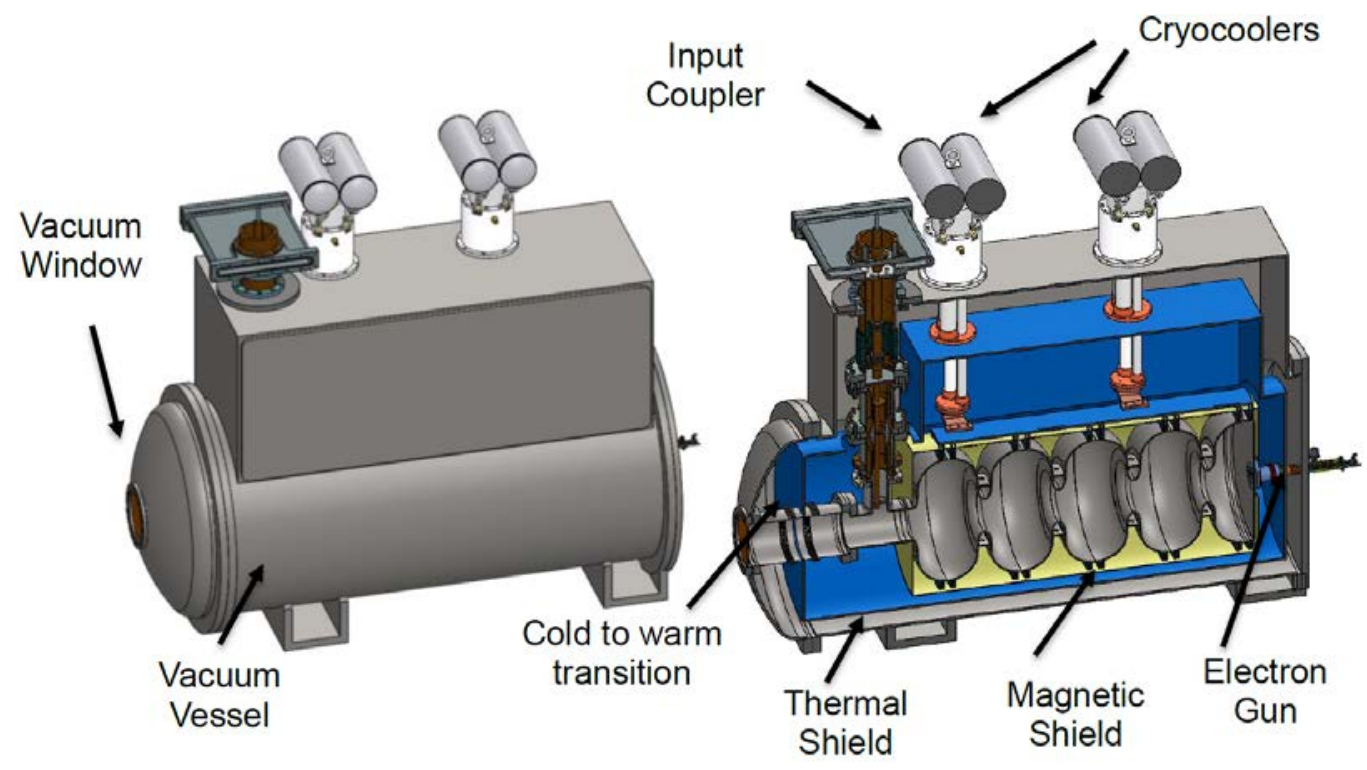

Figure 4f.1: Horizontal Cryostat concept design showing a vacuum vessel, thermal shield and magnetic shield encompassing a single 41/2-cell $650 \mathrm{MHz}$ superconducting cavity

\section{g. Thermal and Magnetic Shielding}

The $650 \mathrm{MHz} 41 / 2$-cell cavity will be surrounded by a thermal shield. It will operate near the 1st stage temperature of the cryocoolers and provide RF coupler and electron gun 
intermediate temperature heat intercepts. Our calculations and drawings use a conservative temperature of $70 \mathrm{~K}$ but we believe the 1st stage can and should allow the shield to operate lower (more like $60 \mathrm{~K}$ ) to minimize $4 \mathrm{~K}$ heat loads.

The maximum outer diameter of the $650 \mathrm{MHz}$ cavity is $\sim 450 \mathrm{~mm}$. The length of the cavity is $\sim 1.25 \mathrm{~m}$ and the diameter of the thermal shield is $\sim 590 \mathrm{~mm}$. The length of the shield is $\sim 1.5 \mathrm{~m}$. The cavity is assumed to be cooled by two $3 \mathrm{~W}$ cryo-coolers. The $2 \mathrm{nd}$ stage $(4 \mathrm{~K})$ of the cryocoolers penetrate the thermal shield through circular openings which serve to anchor the shield temperature near that of the cryocooler 1 st stage.

RF power for the cavity excitation is delivered through a coaxial coupler which includes a thermal intercept connected by the radiation shield to the cryocooler 1st stage.

To maintain high $Q$ in the SRF cavity, it must be shielded from the static magnetic fields including those due to the Earth. The desired maximum density of the magnetic flux on the walls of the cavity is $<5 \mathrm{mG}$. Nine cell, $1.3 \mathrm{GHz}$, cavities for the LCLS-II accelerator are routinely magnetically shielded to the level of $\sim 5 \mathrm{mG}$ in their 8-cavity cryogenic modules. To reach this level of the flux density for LCLS-II, the following steps were used $\left[{ }^{14}\right]$ :

- The cryogenic vessel was made of low-carbon steel and demagnetized

- A compensation winding was employed to cancel the longitudinal component of the shield;

- Two layers of one-millimeter thick magnetic insulation were added just outside of the LHe vessel of the cavities.

Similar measures are envisioned to magnetically shield the cavity in this accelerator. However, it should be noted that since a $4 \frac{1}{2}$ cell $650 \mathrm{MHz}$ cavity is about twice the diameter and about the same length as the LCLS-II cavity, similar shielding effectiveness will require magnetic shielding about twice as thick $\left[{ }^{15}\right]\left[{ }^{16}\right]$. Penetrations for the RF power coupler and cryocoolers must also be equipped with a properly configured "chimney" to prevent local flux penetration.

One advantage of this accelerator vs the LCLS 8 cavity cryogenic module is its shorter length, which simplifies shielding of the longitudinal component of the field. There are several possible approaches to magnetic shielding for this accelerator. The final shielding solution will be chosen after an engineering and cost analysis of several options is made. An optimal approach to the shielding design would be to integrate this effort with the

14. I. Terechkine, "Options for improving the effectiveness of magnetic shielding in the LCLS-II cryomodule", FNAL TD note TD-14-006, Nov., 2014.

15. A.C. Crawford, "Magnetic System Update for the LCLS-II Superconducting RF Cavity", note, May 27, 2014.

16. D. L. Hall, et al., "Impact of trapped magnetic flux and thermal gradients on the performance of Nb3Sn cavities", IPAC-2017, proceedings, pp. 1127 - 1129. 
mechanical design optimization. It may be that the $<5 \mathrm{mG}$ requirement for the remnant magnetic field may be on the conservative side for $650 \mathrm{MHz}$ and it may be possible to relax that requirement after tests like those in are made with a $650 \mathrm{MHz}$ cavity coated with $\mathrm{Nb}_{3} \mathrm{Sn}$.

Another important consideration in the accelerator design is control of trapped flux due to magnetic fields generated by thermal currents due to dissimilar metals ( $\mathrm{Nb}_{\mathrm{vs}} \mathrm{Nb}_{3} \mathrm{Sn}$ ) at the cavity surface. Recent studies at Cornell $\left[{ }^{16}\right]\left[{ }^{17}\right]$ indicate that to avoid increases in the residual resistance due to flux trapping from thermal currents, the cavity must be cooled slowly though the $\mathrm{Nb}_{3} \mathrm{Sn}$ transition temperature of $18 \mathrm{~K}$ and perhaps through the $9 \mathrm{~K} \mathrm{Nb}$ Tc transition. We envision adding a heater to the each cryocooler thermal connection to the cavity to allow precise control through these temperature regions.

\section{h. RF Power Source}

Since losses in the superconducting acceleration structure are very small, a total of 250 $\mathrm{kW}$ of $\mathrm{RF}$ input power is required for beam acceleration. A small additional amount (e.g. $10 \%$ ) of RF power will be required for control and regulation. The frequency and phase of the RF input of the RF gun will be determined using signals from a pickup in the acceleration cavity. Precise amplitude and phase control of the RF are not needed since there is not a requirement for precise control of the accelerator output energy. It is likely that beam loss control in sweeping magnets may be what sets the overall energy spread requirements. A small fraction of the power from the RF source will be directed to the gun. A small signal at the operating frequency of $650 \mathrm{MHz}$ (from the probe, for example) will go to a frequency multiplier and then to a solid-state amplifier to create the second harmonic $(1300 \mathrm{MHz}$ ) for the RF gun. The phase of the first harmonic and the second harmonic can be adjusted at low power levels to allow optimization of injection and acceleration.

To meet the overall cost/Watt and efficiency targets for the accelerator ( $\$ 10 /$ Watt and $>50 \%$ efficient) the selection of the RF source is crucial. Possible options include 1) solid - state amplifier, 2) Inductive Output Tube (IOT), or 3) a magnetron.

1. Modest power solid-state RF amplifiers are reliable and modular but costs are high. For example, RK, Japan, currently supplies $1300 \mathrm{MHz}, 4 \mathrm{~kW}$, CW solid state amplifiers for the LCLS II project at $>\$ 6 / \mathrm{W}$. Individual solid-state devices can have very long lifetimes (> 20 years). However, a $250 \mathrm{~kW}$ RF supply will be made up of many lower power devices operating in parallel. This can provide reliability if the lower power modules

17. D. L. Hall, M. Liepe, "High Performance Nb3Sn Cavities", WEXA 01, proceeding of SRF 2017 Conference, Lanzhou, China. 
are designed to fail safe and redundant modules are built in. However, for RF power supplies delivering hundreds of $\mathrm{kW}$, such supplies become increasingly complicated, as it is necessary to add many outputs in phase and to protect against various cascade failure modes. This further increases costs and may reduce the overall RF source reliability. Also, since individual SS devices have a limited production lifetime, a large compliment of "initial spares" may have to be purchased. We estimate that the base cost of a 250-kW solid state amplifier will cost $>\$ 1.5 \mathrm{M}$, making it impossible to hit the required target cost of $\angle \$ 2 \mathrm{M}$ for each 250-kW accelerator module. (Recall that $4+1$ spare modules are used to produce 1 MW and must, in total, cost less than the $\$ 10$ M Type 3 FOA target cost). Finally, a solid state $250 \mathrm{~kW}$ amplifier will be physically large and have poor wall-plug power efficiency at this frequency (about 50-60\%), making it difficult to hit overall accelerator efficiency goals.

2. An Inductive Output Tube (IOT) is much smaller in size and more robust than solid state amplifiers. However, the cost is still above $\$ 6 / \mathrm{W}$. Longevity is typically $\sim 25,000$ hours, or about 3 years. After that, the tube must be replaced and refurbished (cathode and grid). However, the cost of the refurbished tube is significantly lower than the purchase price. The wall-plug efficiency at this frequency is also about $50-60 \%$.

3. A magnetron RF source potentially provides much higher efficiency, $(>80 \%)$ at considerably lower cost of RF, $\sim \$ 1 / \mathrm{W}$ than the aforementioned sources. The magnetron should operate in injection-locked mode. The physical size of this RF source is acceptable. However, magnetrons have low longevity compared to an IOT or a solid-state amplifier. Current magnetron longevity is $7,000-10,000$ hours, limited by the cathode life time. Significant efforts are necessary to optimize magnetron operation, in the injection - locked mode, to reduce the electron bombardment of the cathode, increase lifetime, and improve the tube efficiency.

\section{i. $\mathrm{Nb}_{3} \mathrm{Sn}$ Coated Cavities}

Use of a superconductor with higher transition temperature (Tc) such as $\mathrm{Nb}_{3} \mathrm{Sn}(\mathrm{Tc}=$ $18 \mathrm{~K}$ ) can dramatically increase the efficiency at $4 \mathrm{~K}$ compared to a pure Niobium cavity ( $\mathrm{Tc}=9 \mathrm{~K}$ ). As stated previously, a $1.3 \mathrm{GHz}$ single cell niobium cavity coated with $\mathrm{Nb}_{3} \mathrm{Sn}$ has been demonstrated at Cornell University at gradients of $14 \mathrm{Megavolts} / \mathrm{m}$ with a quality factor of $2 \times 10^{10}$ at $4^{\circ} \mathrm{K}$. Figure $4 \mathrm{i} .1$ illustrates performance of another $\mathrm{Nb}_{3} \mathrm{Sn}$ coated cavity recently tested at Cornell illustrating both the higher gradient (18 MV/M) currently achievable with $\mathrm{Nb}_{3} \mathrm{Sn}$ and the $\times 20$ improvement in efficiency at $4 \mathrm{~K}$ compared to pure a $\mathrm{Nb}$ cavity. ${ }^{[17]}$ Recent Cornell studies also indicate that thin spots in the $\mathrm{Nb}_{3} \mathrm{Sn}$ coating create hot spots that limit gradient performance and lead to lower Qs than for uniformly thicker coatings. Recent research also indicates that the cavity $Q$ is degraded due to flux pinning by external magnetic fields, necessitating good magnetic shielding against external fields. In addition, it is suspected that thermo-currents resulting from dissimilar materials ( $\mathrm{Nb}$ vs $\mathrm{Nb}_{3} \mathrm{Sn}$ ) during cool down can lead to magnetic fields and trapped flux. It is likely 
that both issues can be improved by good external field shielding and by slowing the cool down rate through Tc. However, even with no improvement, from existing work, we can reliably predict that a $650 \mathrm{MHz} 4.5$ single cell accelerator cavity operated at $\sim 10 \mathrm{MV} / \mathrm{M}$ will dissipate less than $2.5 \mathrm{~W}$ at $4 \mathrm{~K}$. This low $4 \mathrm{~K}$ heat load will enable efficient, simple conduction cooling of the cavity via commercial $4 \mathrm{~K}$ cryocoolers. Vigorous efforts are also underway at Cornell, Jefferson Lab, and at Fermilab (see Figure 4i.2) to improve the $\mathrm{Nb}_{3} \mathrm{Sn}$ coating process and to extend it to multicell cavities including those at $650 \mathrm{MHz}$.

The use of $\mathrm{Nb}_{3} \mathrm{Sn}$ coated cavities is one of the key enabling advancements that allows our concept to be viable. Currently, development of Nb3Sn coated cavities is well supported by DOE (OHEP and NP) but a sustained effort in this area is crucial to the realization of accelerator concept presented in this report.

\section{(1) Comparison to niobium}

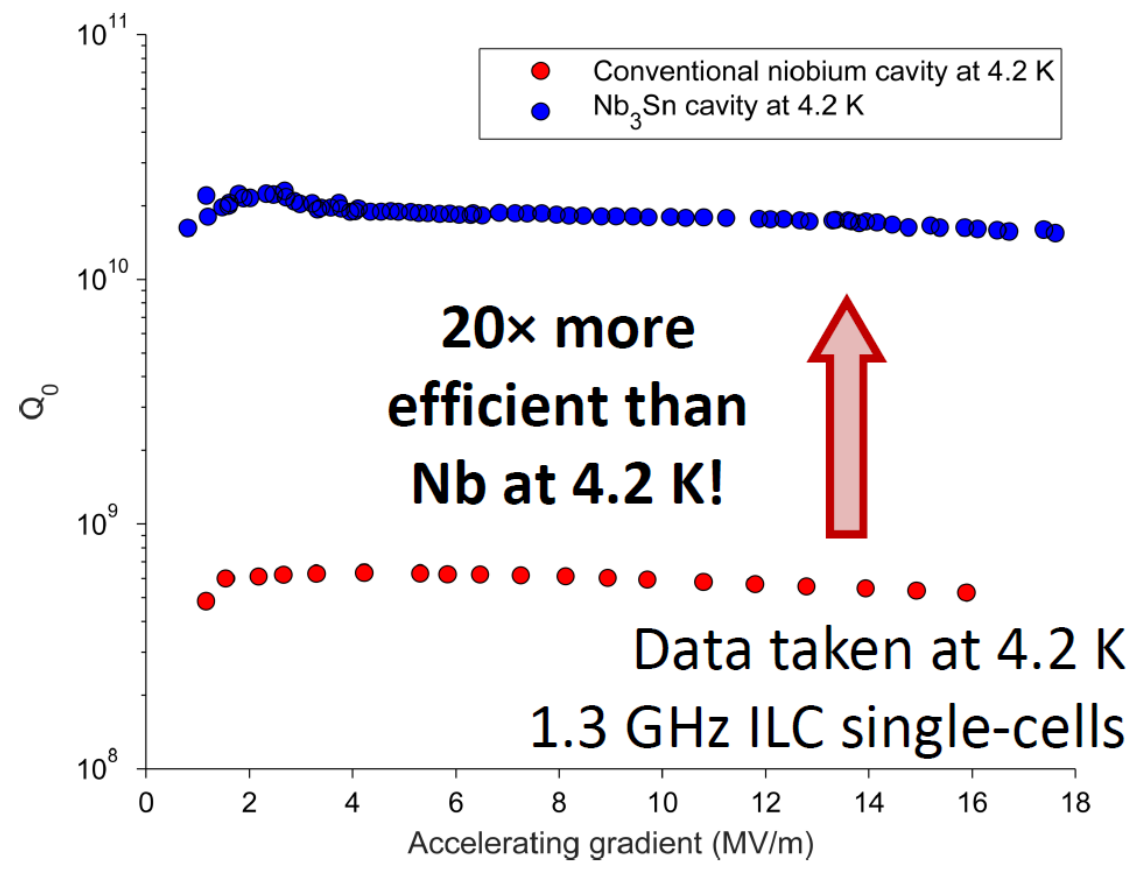

Figure 4i.1: Nb3Sn vs Nb Efficiency comparison from D. Hall, SRF2017 


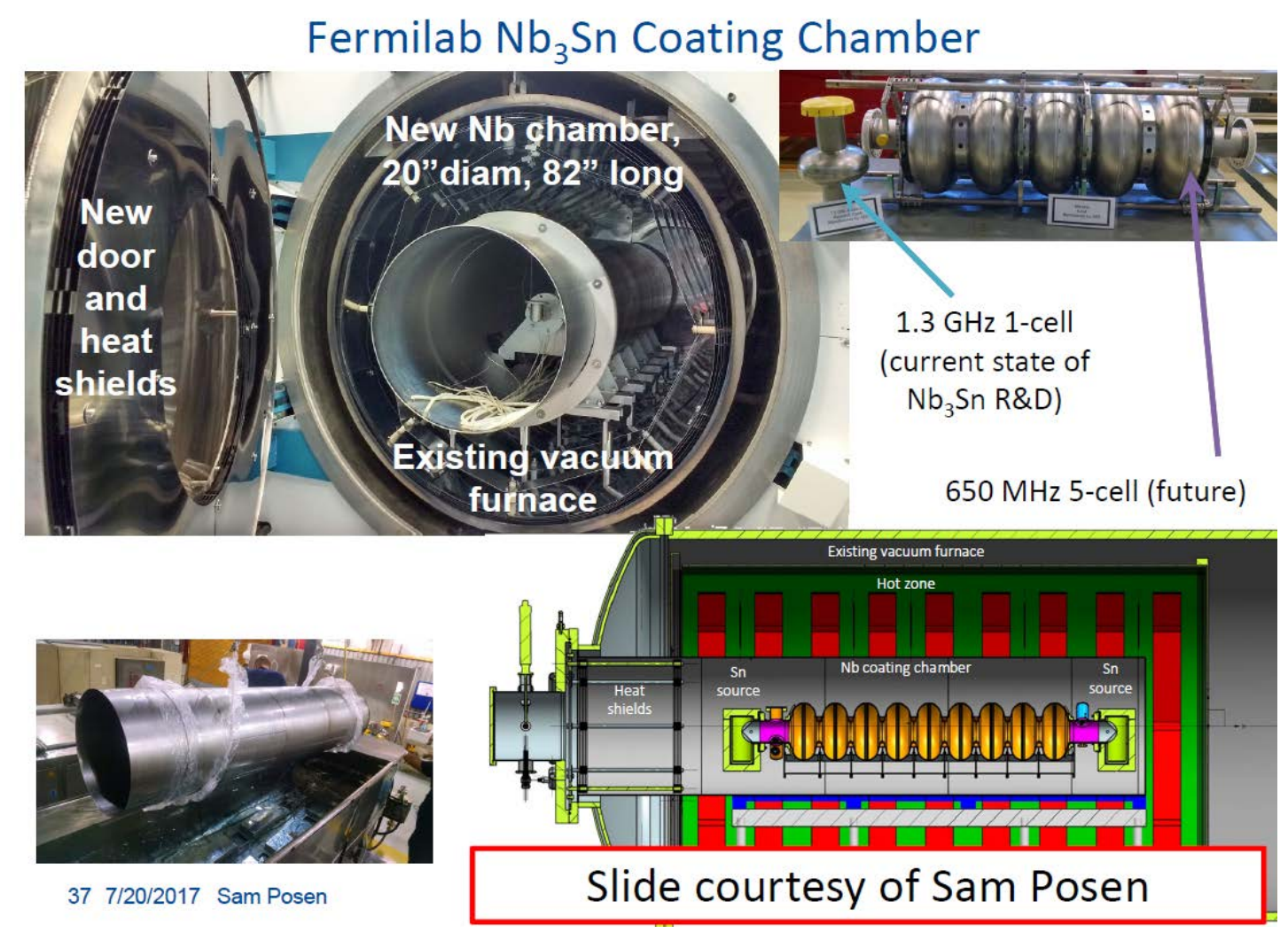

Figure 4i.2: Nb3Sn development program at Fermilab from D. Hall, SRF2017

\section{j. Conduction Cooling}

A $4 \frac{1}{2}$-cell $650 \mathrm{MHz}$ cavity is constructed of high purity Niobium and coated internally with $\mathrm{Nb}_{3} \mathrm{Sn}$. The outside of this cavity is thermally connected in multiple places to the second stage of a pair of $3 \mathrm{~W} @ 4 \mathrm{~K}$ two-stage cryocoolers, which serve as the $4 \mathrm{~K}$ heat sink instead of liquid helium. (Note: $2.5 \mathrm{~W}$ units exist and $3 \mathrm{~W}$ units are currently under development by CryoMech). The first stage of the cryocoolers operates near $60 \mathrm{~K}$ and provides thermal intercepts for the RF coupler, electron gun, mechanical supports, and thermal radiation shields. Such a system is simple, compact, and efficient compared to systems based on the use of liquid cryogens. In the horizontal configuration, the cryocoolers are mounted directly on top of the vacuum vessel. A preliminary estimate of the $4 \mathrm{~K}$ heat load on the $4 \frac{1}{2}$ cell $650 \mathrm{MHz}$ cavity is $\sim 2.5 \mathrm{~W}$ at $4 \mathrm{~K}$ corresponding to about $\sim$ $0.5 \mathrm{~W}$ per cavity cell. 

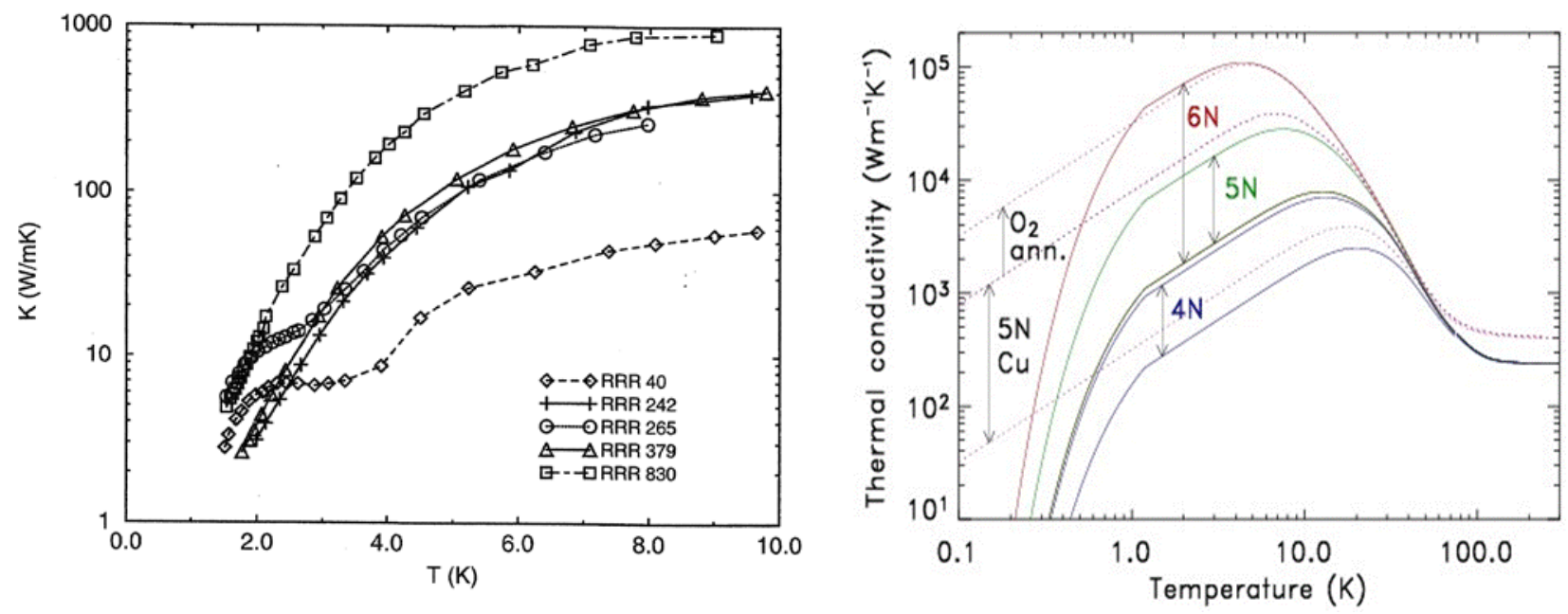

Figure 4j.3: Published values of thermal conductivities of SRF grade niobium (left) and high purity aluminum (right)

Achieving low thermal contact resistance is also crucial to our design. Poor mechanical contact, oxides or dirt on surfaces, improper interstitial materials, or insufficient pressure at joints can lead to significant temperature drops across joints. Using a $4 \mathrm{~K}$ cryocooler, we measured the thermal contact resistance for $\mathrm{Al}$ to $\mathrm{Al}$ and $\mathrm{Al}$ to $\mathrm{Nb}$ joints. The temperature drop across a joint was measured as a function of heat flow through the joint and vs temperature.

Using our measured thermal conductivity and thermal resistance data, the temperature differential for the complete thermal path from a cavity cell to cryocooler head was also estimated.

\section{k. Accelerator Controls Needed for Reliable Turn-Key Operation}

As the ultimate users of the device will include operators of water and waste treatment plants, the Accelerator control system must be designed for turnkey and highly reliable operation. For each $250-\mathrm{kW}$ acceleration module, we envision an independent, robust, and intelligent control system with remote diagnostics that can maintain stable operation for long periods of time without intervention by experts.

The control system's major functions are: 1) to control the phase and amplitude of the fundamental RF frequency $(650-\mathrm{MHz})$ in the presence of beam loading to maintain the beam output energy; 2) to control the primary and second harmonic and the thermionic cathode in the gun to control the output current and thus the beam power; and 3 ) to monitor beam diagnostics and interlocks to provide machine and personnel protection.

The system goal is to operate at $10-\mathrm{MeV}$ and at a constant power. Continuous monitoring of both the beam current and supplied RF power will allow us to ensure a constant beam power and energy. The control system must also facilitate adjusting the beam power levels at the request of the user and facilitate automatic startup, stand-by, and shutdown of the accelerator at the request of the user. Our RF control scheme 
assumes that the drive frequency of the $650-\mathrm{MHz}$ cavity will be adjusted to track the cavity's resonant frequency via tracking of an off-resonance phase modulated sideband. For the thermionic cathode option, a model of the relationship between the cathode field, cathode temperature, and the resultant beam current will be created using both simulation and (once the system is commissioned) measurement results. In this case, the system will continually monitor the cathode temperature, RF field, and downstream current monitor to update the model. Model predictive control using power and current measurements, RF controls, and the cathode heater settings will be used for the RF ramp during the turn-on process. For the field emitter cathode option, we would need to track, correlate, and control the output current with respect to the gating voltages. Control of cathode and gun subsystem is critical, so we envision building and testing a $1 \frac{1}{2}$ cell gun to validate design choices before building the first article $4 \frac{1}{2} 2$-cell accelerator.

The control execution will primarily occur in firmware (e.g. FPGAs). For the first article test accelerator, we envision that the user interface will be coded in LabVIEW, and the data acquisition system will use NI data acquisition modules. The control architecture will be designed to accommodate a variety of RF sources, as we will likely start testing the SRF gun and test accelerator with COTS RF power systems based on IOTs or solid state systems before purpose-designed $650 \mathrm{MHz}$ magnetron RF sources are available. The machine protection system will monitor the cryocooler, temperatures, beam current, cathode temperature (for a thermionic cathode), and the RF field readings. We will have real-time radiation monitors (e.g. ionization chambers) near the bio-solids waste stream to measure beam power for system tune-up and for continuous verification of the applied dose.

Before construction and experimental testing, the entire system will be modeled using both high-fidelity numerical models and simple engineering models as our team has done recently with other accelerator systems. Together, these models will be used to assist in the development and testing of the control system design and implementation. Testing the control system in this way will also enable any unforeseen diagnostics requirements or problematic system design settings to be identified prior to construction of the system.

To test and characterize the first article test accelerator system we envision a spectrometer with a Faraday cup and screen to measure the beam energy and the current. To enable the tune-up process as well as for use in maintaining beam during production operation we envision that each module will have a current and beam position monitor.

Beam loss detection could be accomplished by measuring the Cerenkov light generated by electron strikes to an optical fiber. The opening angle of Cerenkov radiation in a fiber above about 6-MeV is such that the light is nearly all contained in the fiber optic due to total internal reflection and the observed intensity scales purely by the number of electrons hitting the fiber and their path length inside the material. The fibers will run along the length of a device where electron beam loss is expected. The Cerenkov signal can 
then be detected with sensitive photodiodes at the end of each of the irradiated fibers. Measurement of the signal can be used in the machine protection system. Employing such a Cerenkov light system would allow real- time monitoring of loss location and loss intensity during commissioning the test accelerator. (see References $\left[{ }^{18}\right]\left[{ }^{19}\right]$.)

\section{Beam Diagnostics}

For an industrial accelerator, it is important to minimize the instrumentation required for control during stable operations and for fault diagnosis, because such systems have costs that will contribute significantly to the overall accelerator module cost. However, for the first article test accelerator, a larger set of beam diagnostic instrumentation will be required to assist with commissioning the machine and understanding its performance.

Below is a list of beam diagnostic equipment envisioned for the first article test accelerator.

1. Cavity:

- Probe for RF amplitude and phase measurements

- $4 \mathrm{~K}$ temperature sensors on the cavity and thermal links

- Fluxgate field measurement devices to measure effectiveness of magnetic shields

- Beam vacuum sensors

- Heater for warm up and thermal testing with RF off

2. RF gun:

- $650 \mathrm{MHz}$ probe for diagnostics and control (amplitude and phase)

- $1.3 \mathrm{GHz}$ probe for diagnostics and control of $2^{\text {nd }}$ harmonic (amplitude and phase)

- DC bias measurement and control

- Cathode heater voltage and current measurements;

- Temperature sensors on key gun components

- Forward/reflected power measurements

18. A.L. Edelen, S.G. Biedron, B.E. Chase, D. Edstrom, S.V. Milton, P. Stabile, 2016, "Neural Networks for Modeling and Control of Particle Accelerators," IEEE Transactions on Nuclear Science 63(2), 878-897.

19. P. Edelen, D. Bowring, B.E. Chase, and J. Steimel (FNAL), A.L. Edelen, S.G. Biedron, and S.V. Milton (CSU), "First Principles and J Modeling of RFQ Cooling Systems and Resonant Frequency Responses for Fermilab's PIP-II Injector Test," in IEEE Transactions on Nuclear Science , Early Access, doi: 10.1109/TNS.2016.2644663. 
3. RF Coupler:

- Measurement and control of DC bias

- Optical probe to detect discharges

- Temperature sensors

- Air flow control

4. RF feed from RF source to the cavity:

- Directional coupler and probes

5. RF source:

- Input power control (forward/reflected)

- HV (if necessary)

- Heater (if necessary)

- Water control

6. Beam control:

- Current sensor

- BPM

- Ionization chamber

- Thermocouples

7. Focusing and steering system

- Lens input voltage and current

- Steering voltage and current

- Thermocouples, 4-6 (beamline, window)

- Vacuum

8. Cryocoolers diagnostics and control

9. Beam loss monitors

10. Machine protection interlocks

11. Personnel protection interlocks

\section{m. Beam Delivery System}

To integrate an industrial EB accelerator to treat bio-solids into a municipal wastewater processing facility such as those operated by MWRD, it is important to design a Beam 
Delivery System (BDS) that: 1) ensures that all the material in the treated bio-solid stream receives at least the minimal desired dose (assumed to be $10 \mathrm{kGy}$ ); 2) ensures that electron beam power is used efficiently by arranging for the beam to be completely absorbed by the target material; and 3) Limits the dose range above minimum to avoid inefficiencies associated with overdosing material.

Figure $4 \mathrm{~m} .1$ shows the concept we have developed to irradiate bio-solids with modular accelerators. The basic scheme is that compact SRF accelerators are housed in separate enclosures above the irradiation area. The electron beam from each redundant accelerator module is delivered vertically into the target enclosure, then bent at an angle towards a vertically falling bio-solids stream by a bending magnet. The beam is also rastered to create a fan beam that is slightly wider than the falling bio-solids stream. The raster speed is very high (few $\mathrm{kHz}$ ) compared with the vertical velocity of the bio-solids stream and the beam spot size $(\sim 1 \mathrm{~cm})$ is such that each raster scan has a large overlap with the previous raster scan. This ensures that the beam from each accelerator module completely illuminates the falling bio-solids stream.

Figure $4 \mathrm{~m} .2$ shows the absorbed dose in water and plus $25 \%$ bio-solids for an incident $10 \mathrm{MeV}$ electron beam. The red dotted line indicates the minimal dose that any part of the waste stream must experience (10 kGy) meet the requirements of a class A sludge. The thickness of the waste stream that can be treated with a $10 \mathrm{MeV}$ beam is about $28 \mathrm{~mm}$ for $25 \%$ bio-solid mixture. The average dose deposited in this $28-\mathrm{mm}$ stream as the beam passes through it is about $12 \%$ on average above the minimal required dose. By design, the fraction of the beam (20\%) that fully penetrates the waste stream is absorbed by the horizontal waste stream below, ensuring the entire beam is used efficiently to both further sanitize the bio-solids and to remove additional organics and or pharmaceuticals. The required total accelerator beam power is $1 / 0.71$ times the minimum power that must be put in the waste stream at $10 \mathrm{kGy}$. For a flow of $27 \mathrm{~kg} / \mathrm{sec} \rightarrow(27 \mathrm{~kg} / \mathrm{s} \times 10,000 \mathrm{~J} / \mathrm{kg} / 0.71)=$ $380 \mathrm{~kW}$.

The vertical velocity of the stream is largely determined by pressure in the delivery pipe and by gravity; thus, it can be well known. Control of the EB power of each module, the number of modules operating, raster rate, beam spot size, and number of modules turned on all provide precision control of the overall dose and built-in growth paths to add capacity in a facility as needed.

In our concept, the bio-solids (after the centrifuge in MWRD) are pressurized allowing material to flow into the target enclosure in pipes and then be extruded, much like toothpaste from a tube, to form the wide, thin falling sheet that is targeted. After the Irradiation, the bio-solids land and are transported out of the enclosure on a conveyor belt. This transport transition is very similar to that which already occurs in the MWRD Stickney plant. Radiation shielding protects plant workers outside the enclosure. The bio-solids enter and exit the enclosure via labyrinths. Access to the target enclosure is 
controlled as part of the personnel accelerator safety interlock system.

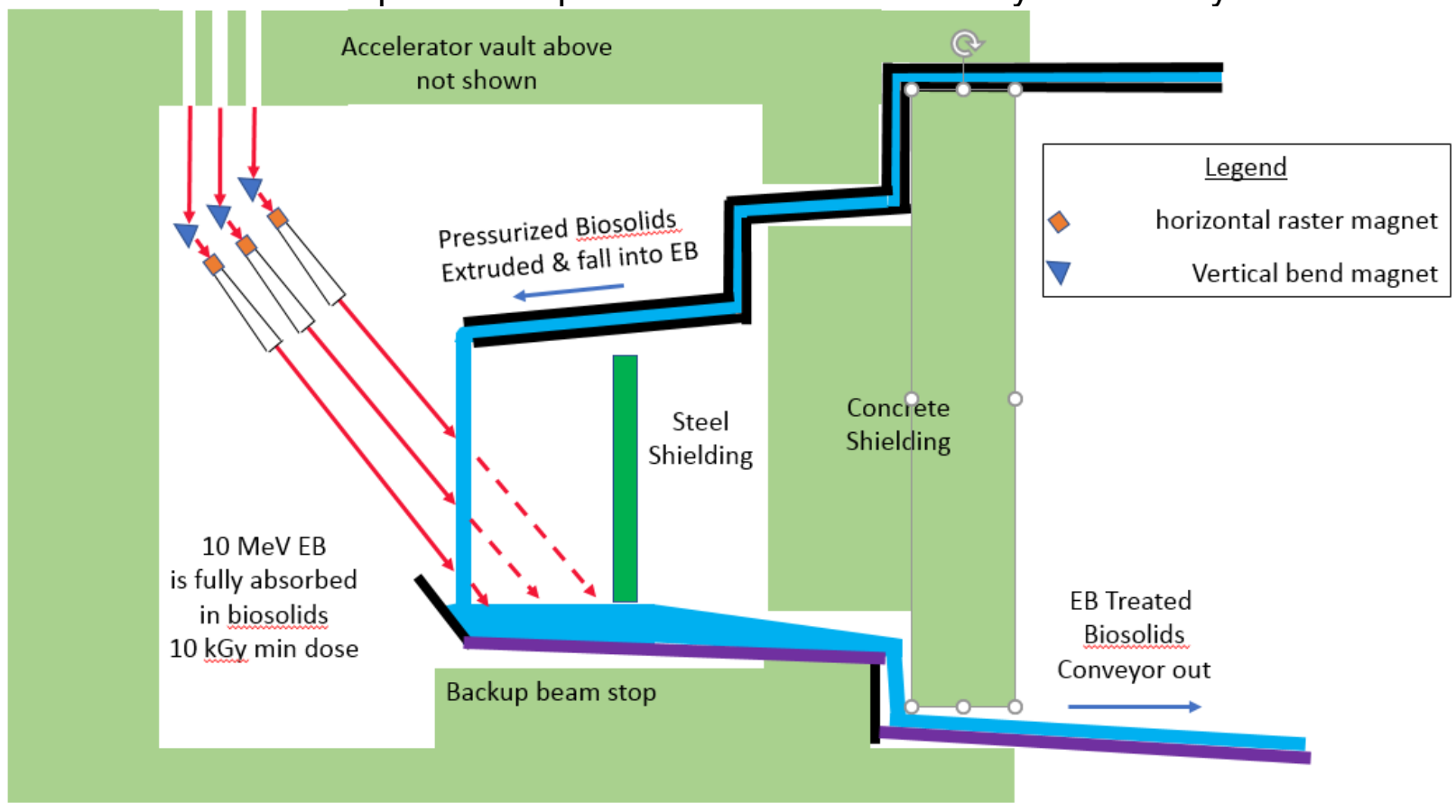

Figure 4m.1: Bio-solids target enclosure schematic and radiation shielding concept

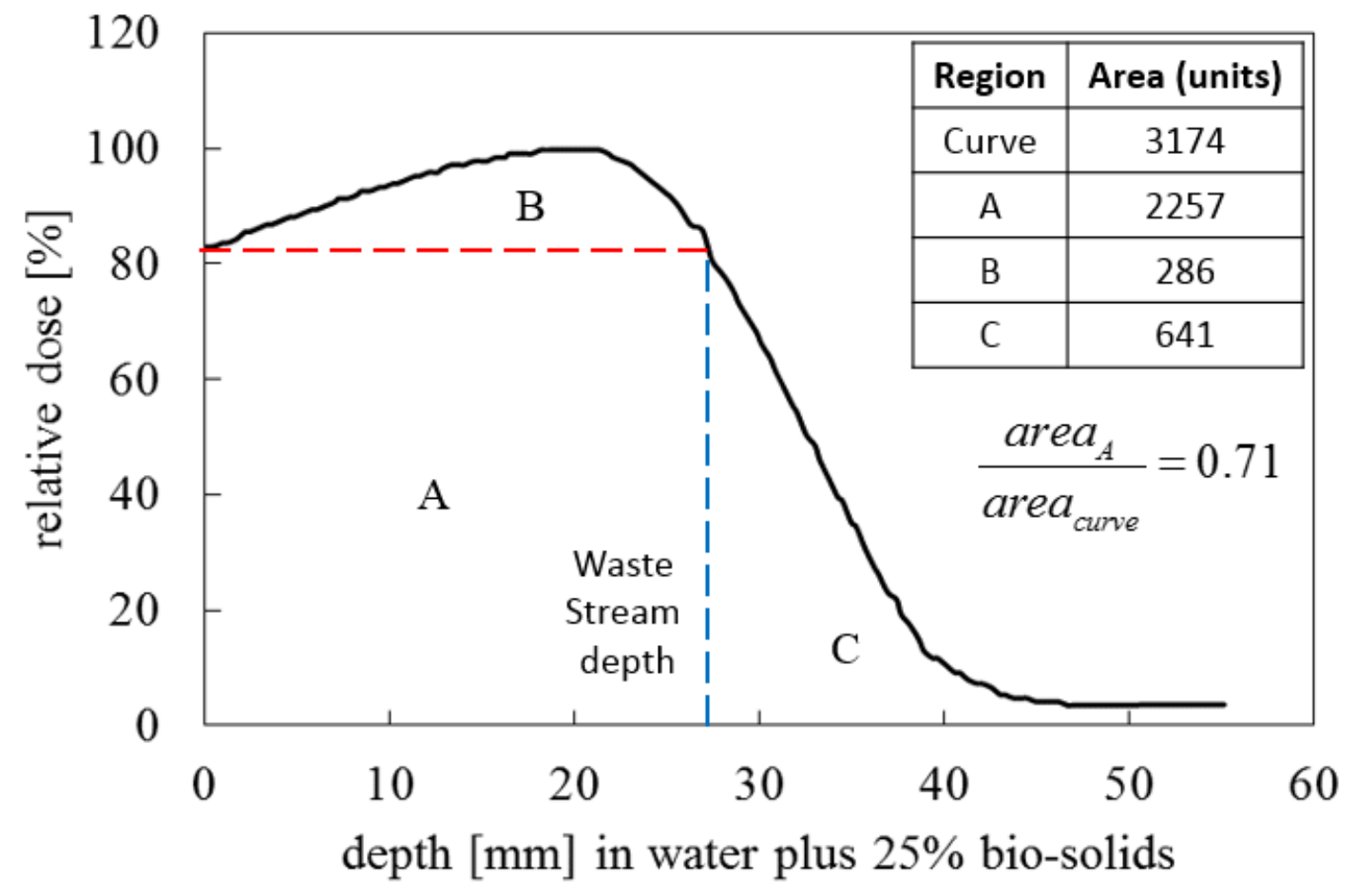

Figure 4m.2: Deposited dose vs depth for $10 \mathrm{MeV}$ EB in water that includes 25\% bio-solids.

Accelerator vaults are located above the target enclosure and are shielded and interlocked such that any accelerator module can be serviced or replaced while the other modules are in full operation; this is a key feature to ensure high overall system up time. 
The systems inside the target enclosure are deliberately made very simple and vacuum windows, etc. are kept well away from the waste stream to ensure high reliability. Conveyor belt motors are located outside the enclosure and the mechanical systems inside are minimized.

For the example of the MWRD Stickney plant (world's largest) the $25 \%$ bio-solids waste stream flows at 0.5 MGD. This corresponds to an extruded mass flow (è) of 5.8 gallons per second or about $\dot{e}=27 \mathrm{~kg} / \mathrm{s}$ assuming the solids have density 2 . An exposure of $10 \mathrm{kGy}$ $(10,000 \mathrm{~J} / \mathrm{kg})$ at this flow rate requires a minimum beam power of $270 \mathrm{~kW}$ into the falling stream if the dose were perfectly uniform and completely absorbed by the waste stream. However, there are non-uniformities and inefficiencies that must be accounted for, leading to a required accelerator power higher by $\sim 40 \%$ (i.e. $1 / 0.71$ ) or $\sim 380 \mathrm{~kW}$ total. To that, we would add spare capacity in the form of at least one spare accelerator module (note that for this MWRD waste stream, a $250 \mathrm{~kW}$ Accelerator module size is not optimal). A better choice might be $3 \times 200 \mathrm{~kW}$ modules with two operational and one hot spare.

We can estimate the required target stream width and velocity from

$$
\dot{\mathrm{e}}=t w d \dot{\mathrm{z}}
$$

Where $t$ is the thickness of the extruded bio-solid stream, $w$ is its width, $d$ is the density of the stream and $\dot{z}$ is the speed of the extruded waste stream. For a 1 meter wide stream that is $3.2 \mathrm{~cm}$ thick $\rightarrow$

$$
\begin{gathered}
27 \mathrm{~kg} / \mathrm{s}=(3.2 \mathrm{~cm})(100 \mathrm{~cm})(1.25 \mathrm{~kg} / \text { liter })\left(1 \text { liter } / 1000 \mathrm{~cm}^{3}\right) \dot{\mathrm{z}}(\mathrm{cm} / \mathrm{sec}) \\
\text { or } \dot{\mathrm{z}}=67 \mathrm{~cm} / \mathrm{sec}=\sim 2 \mathrm{ft} / \mathrm{sec}
\end{gathered}
$$

Given that the Stickney facility is the largest in the world, we conclude that this is a manageable flow rate such that our overall beam delivery concept is viable.

\section{n. Radiation Shielding}

We simulated $1 \mathrm{MW}$ of $10 \mathrm{MeV}$ electron beam power interacting with a bio-waste stream inside an encased concrete structure to calculate the prompt dose rates on the outside of the shielding (note that the expected beam for the dewatered bio-solids is only $380 \mathrm{~kW}$ so these estimates are conservative for that case and closer to the 2 MGD WAS flows at the MWRD Stickney plant). In the simulation, a single electron beam impinges on the target waste stream at an angle and produces prompt radiation primarily in the forward direction which, by design, is largely directed toward the floor of the enclosure. One area of interest is where the EB treated bio-solids conveyor exits the enclosure. Figure 4n.1 illustrates the simplified geometry used for computer simulation. A one foot grid pattern imposed on the concrete shielding allows for an easier estimation of the required concrete thickness. The penetration on the roof represents the hole for the electron beam entry. The purple lines represent the bio-solid flow. For this simulation, we assume the bio-solids enter 
the enclosure by being extruded through a pipe that passes through a labyrinth that is in/out of the plane of figure $4 \mathrm{n} .1$. We assume the bio-solids exit horizontally via transport on a conveyor belt with a vertical labyrinth. This scheme is consistent with the overall biosolids material handling arrangement in the MWRD Stickney plant. In the simulation, we included four 1 " thick steel plates to provide additional shielding for the conveyor exit.

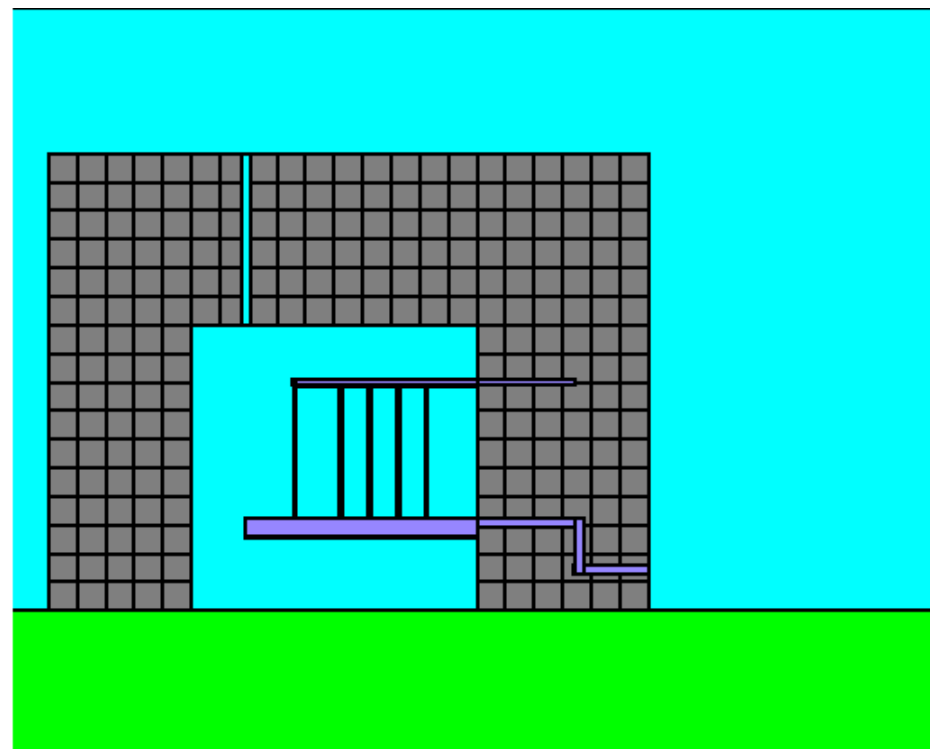

Figure 4n.1: Bio-solids target enclosure schematic and radiation shielding concept

Figure $4 \mathrm{n} .2$ is the result of a low statistics run of the simulation, where we can conclude that with the additional steel plates, 6 feet of forward shielding is adequate. Similarly, 5 feet of shielding in the backward direction is adequate. The color scale of the prompt dose rate is in $\mathrm{mrem} / \mathrm{hr}$, is a log based scale. The simulated prompt dose rate in the forward direction, is about $10 \mathrm{rem} / \mathrm{hr}$ at a depth of 3 feet into the shielding. Extrapolating this through the addition 3 feet of concrete leads to an estimate of $<10 \mathrm{mrem} / \mathrm{hr}$, on the outside surface of the enclosure at the worst place. The roof can be as thin as 3 feet. Further analysis with higher statistics as part of an engineering design effort can likely improve the efficiency of the shielding configuration. 


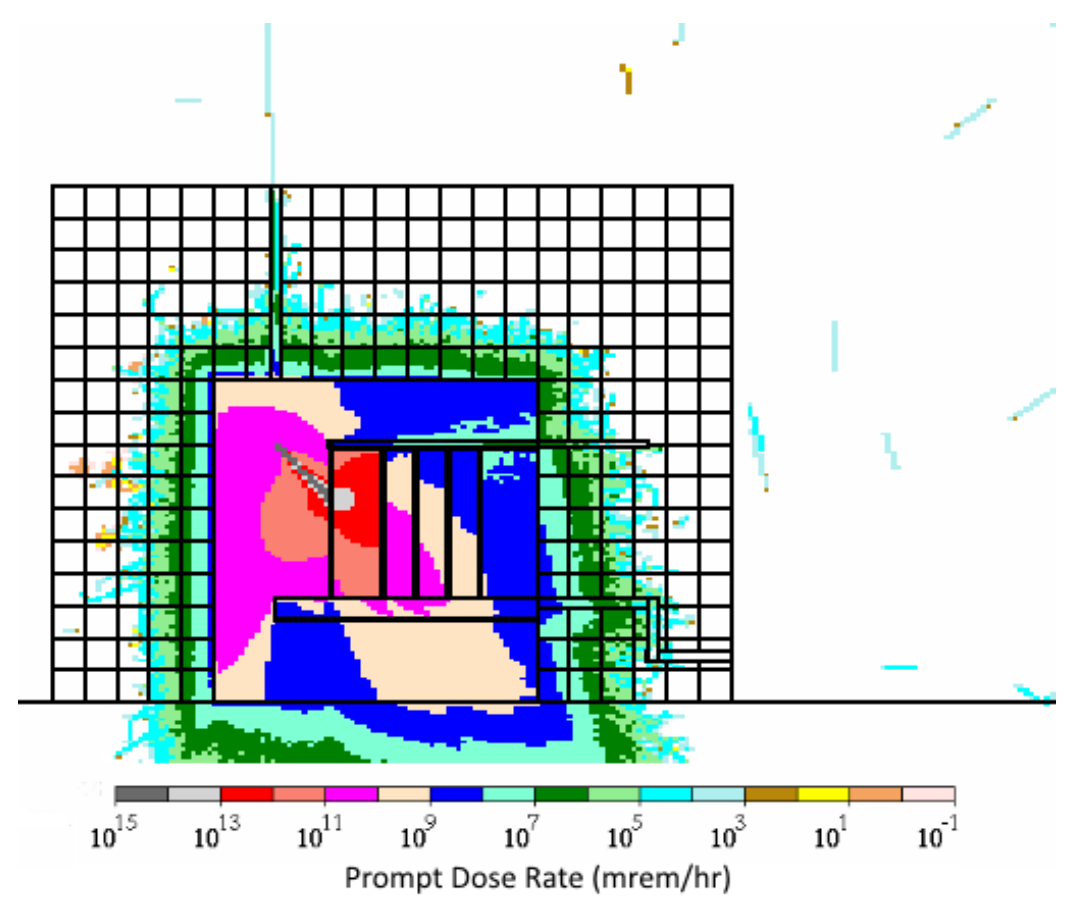

Figure 4n.2: Radiation shielding dose rates for the bio-solids target enclosure schematic Colors represent log scale of prompt dose rate.

\section{R\&D Needed for Key Systems and Technologies}

To transition lab developed breakthroughs in SRF into a viable MW class industrial accelerator, several key technologies require further development. In what follows we assume the goal is an SRF based module capable of producing $250 \mathrm{~kW}$ CW beam for use in either fixed or mobile applications. The enabling R\&D topics are:

A. $\mathrm{Nb}_{3} \mathrm{Sn}$ Coated SRF Cavities: A $1.3 \mathrm{GHz}$ single cell niobium cavity coated with $\mathrm{Nb}_{3} \mathrm{Sn}$ has been operated at Cornell University at gradients of 14 Megavolts $/ \mathrm{m}$ with a quality factor of $2 \times 10^{10}$ at $4 \mathrm{~K}$ demonstrating the feasibility of such cavities. From this work, we can reliably predict that a $650 \mathrm{MHz} 4.5$ single cell accelerator cavity operated at similar gradients will dissipate less than $2.5 \mathrm{~W}$ at $4 \mathrm{~K}$. A laboratory based research effort to manufacture, coat, and test such a $\mathrm{Nb}_{3} \mathrm{Sn}$ cavities at $650 \mathrm{MHz}$ is a critical development effort towards building a first article accelerator based on this technology. Work in this area at $1300 \mathrm{MHz}$ continues at Cornell and a development program has started at Fermilab funded by an early career award. It is important that such efforts receive sustained and adequate funding to transform $\mathrm{Nb}_{3} \mathrm{Sn}$ coating into a reliable and predictable process. A program to coat $650 \mathrm{MHz} \mathrm{Nb}{ }_{3} \mathrm{Sn}$ cavities is needed. After achieving success in the lab with high $Q_{0} 650 \mathrm{MHz} \mathrm{Nb}_{3} \mathrm{Sn}$ prototype cavities, the cavity 
treatment must be further developed into a robust industrial process and transferred to industrial cavity manufacturers.

B. Conduction Cooling and Cryocoolers: Conduction cooling of SRF cavities is a Fermilab proprietary technology (Patent application \#14/689,695) that when combined with commercial cryocoolers enables SRF cavity operation without liquid cryogens. This novel and proprietary configuration (Patent application \#62/234,475) results in dramatic reductions in complexity, size, weight, and cost. Commercial 3W @ 4K (CryoMech) and 5W @4K cryocoolers (Sumitomo) are under active development. However, existing 2 W@4K units (CryoMech) already exhibit sufficient reliability (>40,000 hrs MTBF) that a system using 3 such units can be built today that can reliably support a $4 \mathrm{~K}$ heat budget of $\sim 6 \mathrm{~W}$. Further development of conduction cooling and multi-W cryocoolers can provide a huge benefit by simplifying the cryo-design, lowering costs, and advancing the design towards commercial viability. $R \& D$ is needed to develop cavities optimized for conduction cooling; to develop cavity and coupler heat removal systems optimized conduction; and to fund first purchases from vendors willing to develop $4 \mathrm{~K}$ cryocoolers with higher capacity.

C. Integrated Electron Gun: By integrating the electron gun directly onto the SRF accelerating cavity the overall size and complexity of the accelerator is substantially reduced. Our simulation in this proposal indicates commercial thermionic cathodes can provide the needed beam currents yet introduce very small $(<0.2 \mathrm{~W}) 4 \mathrm{~K}$ heat loads. A $2^{\text {nd }}$ harmonic RF system on the gun leads to very high beam transmission and low beam power losses to cold cavity surfaces. Computer simulation of the resultant beam energy, profiles, and particle losses demonstrate the feasibility of this approach. A key demonstration will be that the electron gun can operate in proximity to a high $Q_{0}$ SRF cavity without degradation of the cavity internal surface. Funds to support SRF gun development are needed before first a first article accelerator can be built. A $650 \mathrm{MHz}$, $11 / 2$ cell SRF gun test facility is the next logical step. Such a facility could be used to optimize the gun design for the proposed accelerator. It can also serve as a long-term test bed for SRF compatible cathode development including both thermionic and Field emission sources.

D. Low Heat Leak RF Power Couplers: RF and thermal simulation indicate that a very low heat leak fundamental RF power coupler is possible that can deliver $250 \mathrm{~kW}$ average power to the SRF cavity with the remarkably low $4 \mathrm{~K}$ load of $<0.75 \mathrm{~W}$ at full power. However, experience indicates that RF coupler development from concept to a robust and practical design often takes years of effort. Similar low loss couplers are being developed at $1300 \mathrm{MHz}$ for lower power inputs. This work will be instructive. However, no very high power $650 \mathrm{MHz}$ low loss couplers are currently under development by the Office of Science. It is important to begin R\&D for such high power low loss couplers at $650 \mathrm{MHz}$ as soon as possible. In addition to industrial accelerators, 
is likely couplers with this new novel design will find many other future uses for other Office of Science projects.

E. Low Cost CW RF Power Source: The use of magnetrons can reduce the cost/Watt of RF power by a factor of 5 while achieving efficiencies more than $80 \%$ leading to substantial cost, weight, and size reductions. Fermilab has demonstrated excellent RF phase and amplitude control with a single cell SRF cavity using proprietary (PCT/US2014/058750) technology based on a single injection-locked, 1-kW, 2.45-GHz magnetron. It is estimated that a project with a commercial RF vendor to create a 150 kW CW $650 \mathrm{MHz}$ magnetron RF source would take 3 years and cost about \$ $3 \mathrm{M}$. A funded research effort to build such RF sources will attract commercial partners since it is likely that such an injection locked magnetron will have many commercial and scientific applications. Although OHEP has funded useful development of injection locked magnetrons, the funded effort has built a device that operates at $1300 \mathrm{MHz}$ and only capable and $60 \mathrm{~kW}$ at $10 \%$ duty-factor Funding development of a fully CW-capable high power ( $150 \mathrm{~kW}$ or more) injection lock magnetron is key to making FOA Type 3 and Type 4 accelerator cost targets achievable.

A multi-year program to develop these technologies is the next logical step to bring a viable MW class SRF-based industrial accelerators to market.

\section{Development Milestones}

[1] Stable operation of a pure $\mathrm{Nb}, 650 \mathrm{MHz}$, single cell cavity; conduction cooled by existing $1 \mathrm{~W}$ cryocooler; and excited with CW RF via beam pipe, demonstrate $1 / 2$ Watt heat removal at $4 \mathrm{~K}$

[2] Stable operation of a pure $\mathrm{Nb}, 650 \mathrm{MHz}$, single cell cavity coated with $\mathrm{Nb3Sn}$; conduction cooled by existing $1 \mathrm{~W}$ cryocooler; magnetically shielded; excited with $\mathrm{CW}$ $\mathrm{RF}$ via beam pipe to $10 \mathrm{MV} / \mathrm{M}$; demonstrate $<1 / 2$ Watt power dissipation at $4 \mathrm{~K}$

[3] Design, build, commission large (big enough for 4.5 cell $650 \mathrm{MHz}$ ) vertical dewar with provisions for two $2 \mathrm{~W}$ CryoMech Cryocoolers, intermediate thermal shield, magnetic shield instrumentation port, gun, RF coupler and beam exit ports.

[4] Stable operation of a pure Nb, $650 \mathrm{MHz}, 1.5$ cell gun cavity; conduction cooled by cryocooler; excited with CW RF via beam pipe. Demonstrate 1 Watt heat removal at $4 \mathrm{~K}$

[5] Stable operation of a pure $\mathrm{Nb}, 650 \mathrm{MHz}, 1.5$ cell gun cavity coated with Nb3Sn; conduction cooled by cryocooler; and excited via beam pipe coupler and CW RF to $10 \mathrm{MV} / \mathrm{M}$ at $4 \mathrm{~K}$ (no beam) 
[6] Commission $650 \mathrm{MHz}$ low power (60 kW) IOT based CW RF power source

[7] Test of $250 \mathrm{~kW}, 650 \mathrm{MHz}$ ultra-low heat leak coupler pair on a test stand.

[8] Stable operation of a pure $\mathrm{Nb}, 650 \mathrm{MHz}, 1.5$ cell gun cavity coated with Nb3Sn; conduction cooled by two $2 \mathrm{~W}$ cryocoolers; and excited with RF via main coupler port to $10 \mathrm{MV} / \mathrm{M}$ at $4 \mathrm{~K}$, with gun operating at $20 \mathrm{~mA}$ average current (about $3 \mathrm{MeV}=60$ $\mathrm{kW})$

[9] Commission $650 \mathrm{MHz}$ high power (300 kW) CW RF power source

[10] Stable operation of a pure $\mathrm{Nb}, 650 \mathrm{MHz}, 4.5$ cell gun cavity coated with $\mathrm{Nb} 3 \mathrm{Sn}$; conduction cooled by two $3 \mathrm{~W}$ cryocoolers; and excited with beam pipe coupler and CW RF to $10 \mathrm{MV} / \mathrm{M}$ at $4 \mathrm{~K}$ (no beam)

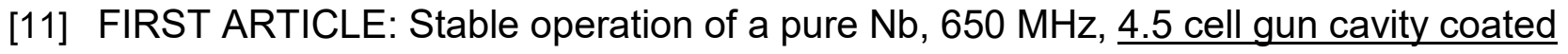
with Nb3Sn; conduction cooled by two $3 \mathrm{~W}$ cryocoolers; and excited with RF via main coupler port to $10 \mathrm{MV} / \mathrm{M}$ at $4 \mathrm{~K}$, with gun operating at $25 \mathrm{~mA}$ average current (about $10 \mathrm{MeV}=250 \mathrm{~kW}$ )

\section{Parametric Cost Estimate}

The FOA cost target is $\$ 10$ per watt for a $1 \mathrm{MW}$ accelerator in production or $\$ 10 \mathrm{M}$ for the $1 \mathrm{MW}$ system. In our scheme, we propose five $250 \mathrm{~kW}$ modules the full output of 4 being sufficient to produce the required $1 \mathrm{MW}$. This establishes a cost target of $<\$ 2 \mathrm{M}$ per module.

Even though a full engineering design is required for a detailed cost estimate, we believe that we have sufficient information from other ongoing projects (e.g. PIP-II, LDRD on conduction cooling, SBIR on $1300 \mathrm{MHz}$ injection locked magnetrons, etc.) to demonstrate that our concept can meet the FOA cost targets.

Our rough cost estimate for a $250-\mathrm{kW}$ module including the basis of estimate and other related information is summarized in Table 7.1. Wherever possible we have based our estimates on recent commercial purchases of similar equipment at Fermilab for other projects. However, the dominate cost is the cost of the RF power source which in this case we assume to be magnetron based. For this estimate we have no commercial experience but rather base our estimates on conversations with $\mathrm{CPI}$ and Calabazas Creek on what such a system might costing in production. The cost of the main RF power coupler is also an estimate scaled from other recent project but may not be appropriate since the proposed couplers has heat leak requirements that are more difficult to achieve compared to recent acquisitions. 
The cost of the accelerator beam distribution system is believed to be small so was not included. Similarly, the cost of a radiation shielded enclosure will be significant but is not included in this estimate since such an enclosure will be both site and application specific.

Better cost estimates will require a full engineering design that fleshes out the details of many of these rough estimates.

\begin{tabular}{|c|c|c|c|c|c|c|}
\hline $\begin{array}{l}\text { Accelerator } \\
\text { module items }\end{array}$ & & $\begin{array}{c}\text { component } \\
\text { detail }\end{array}$ & $\begin{array}{l}\text { unit } \\
\text { cost } \\
\text { (k\$) }\end{array}$ & \# units & $\begin{array}{c}\text { sub } \\
\text { total } \\
\mathrm{kS}\end{array}$ & basis of estimate/comments \\
\hline \multirow[t]{4}{*}{$41 / 2$ cell cavity } & & $\begin{array}{l}650 \mathrm{MHz} \text { cavity, } \\
41 / 2 \text { cell } \\
\end{array}$ & 140 & 1 & & $\begin{array}{l}\text { Eng estimate: } 1300 \mathrm{MHz} \text { cavity is } \$ 100 \mathrm{~K} \text { in } \\
\text { production, } \mathrm{Nb} \text { is } 40 \% \text { of cost, HOM's are } 20 \% \text { of cost } \\
\text { but not needed, } 650 \text { has } \times 2 \text { more } \mathrm{Nb} \text {, adding gun } \\
\text { cavity will not cost much, replaces beam pipe \& large } \\
\mathrm{NbTi} \text { flange } 100-40 \mathrm{Nb}-20 \text { HOM }=>>\text { for } 650 \text { cavity } 40 \\
\mathrm{k} \text { fab cost }+80 \mathrm{Nb}=120 \mathrm{~K} \text {. Guess } \$ 140 \mathrm{k} \text { to be }\end{array}$ \\
\hline & $\begin{array}{l}\text { Bare } \mathrm{Nb} \text { cavity } \\
\text { processing and VTS test }\end{array}$ & & & & 15 & ILC and LCLS-II cavity processing \\
\hline & Nb3Sn coating & & 30 & 1 & 30. & . Eng. estimate \\
\hline & $\begin{array}{l}\text { Nb3Sn coated cavity } \\
\text { VTS test }\end{array}$ & & & & 15 & May be able to skip this \\
\hline \multirow[t]{6}{*}{ electron gun } & & $\begin{array}{l}\text { gun components } \\
\text { and PS's }\end{array}$ & 100 & 1 & 100 & \\
\hline & Thermionic cathode & & 1.3 & 3 & & \\
\hline & DC bias supply & & 2 & 1 & & \\
\hline & supply & & 25 & 1 & & $1300 \mathrm{MHz}$, power =few hundred watts \\
\hline & electrical feed thrus & & 2 & 2 & & RF and DC \\
\hline & Gun Mechanical & & 60 & & & Eng estimate \\
\hline $\begin{array}{l}\text { fundamental RF } \\
\text { power coupler }\end{array}$ & & & 50 & 1 & 50 & $\begin{array}{l}\text { Cost of TTF coupler, this one is simpler, however } \\
\text { higher power }\end{array}$ \\
\hline Cryostat & & simple, no LHe & 220 & 1 & 220 & $\begin{array}{l}\text { Conservative estimate. Assume carbon steel vacuum } \\
\text { tank with flanges, + supports, conduction cooling } \\
\text { links, beam pipe bellow and flanges, pumping and } \\
\text { cryocooler flanges }\end{array}$ \\
\hline magnetic shield & & & 40 & 1 & 40 & Approx cost of double shielded LCLS cavity \\
\hline cryo cooler & $\begin{array}{l}\text { CryoMech 2 W@4k } \\
\text { units }\end{array}$ & $\begin{array}{l}\text { includes } \\
\text { compressor \& }\end{array}$ & 60 & 3 & 180 & $\begin{array}{l}\text { Provide } 7.5 \text { W vs } 5.5 \text { W@ } 9 \mathrm{~K} \text { cryo budget, use current } \\
\text { estimates from CryoMech for } 2.5 \text { W unit }\end{array}$ \\
\hline $\begin{array}{c}\text { Vacuum } \\
\text { equipment }\end{array}$ & $\begin{array}{l}\text { scroll and turbo pump, } \\
\text { valves, readout system }\end{array}$ & & 17 & 1 & 17 & Recent purchases at FNAL \\
\hline $\begin{array}{c}\text { controls/interlocks } \\
\text { and low-level RF }\end{array}$ & & & 130 & 1 & 130 & Eng estimate \\
\hline $300 \mathrm{~kW}$ RF power & COST Driver & & 0.003 & 300 & 750 & $\begin{array}{l}\$ 2.5 / \mathrm{W}, 280 \mathrm{KW} \text { unit provides } 20 \mathrm{KW} \text { of overhead } \\
\text { for } 250 \mathrm{KW} \text { module }\end{array}$ \\
\hline Misc and labor & & & 300 & 1 & 300 & $\sim 1.5$ Man year for assembly and test \\
\hline Module Total & & & & & 1987 & $\begin{array}{l}\$ 10 \mathrm{M} \text { overall cost target for } 1 \mathrm{MW}=\Rightarrow \text { module cost target }=\$ \\
2 \mathrm{M} \text { per } 250 \mathrm{~kW} \text { unit }(5 \text { req) }\end{array}$ \\
\hline
\end{tabular}

Table 7.1: Parametric cost estimate for a single $250 \mathrm{~kW}$ accelerator module in production 


\section{Estimate of Operations Costs}

Operating cost of the $1 \mathrm{MW}$ accelerator can be split into electricity cost, maintenance/repair cost and labor cost. The electricity cost for our machine is from operating the cryo-cooler and operating the RF power system. We assume a 24/7 operation and a $97 \%$ up time. We also assume a $1 \%$ of the capital cost (typically through service contract) towards maintenance and repair. For labor, we assume an average of one full-time operator and one part-time engineer for day to day operation of the machine $\sim$ \$150K per year of labor.

To estimate electrical power costs, assume four $250 \mathrm{~kW}$ module operating at $75 \%$ efficiency. This requires about 1.3 MW of electricity for 8500 hrs @ \$0.07 cost (National Average) or about $\$ 773 \mathrm{k}$ per year. The electricity cost for running two $3 \mathrm{~W}$ cryocoolers $\mathrm{x}$ 5 modules $\times 15 \mathrm{~kW}$ per compressor $=225 \mathrm{~kW}$ would need $\$ 113 \mathrm{~K}$ for a $1 \mathrm{MW}$ machine assuming the cavities in all five modules are cold $100 \%$ of the time. For a wall plug power efficiency of $75 \%$ and $1 \mathrm{MW}$ output power this means $0.3 \mathrm{MW}$ of heat is generated. It costs about $1 \mathrm{~W}$ of electrical power to remove $5 \mathrm{~W}$ of heat so the estimated cost of cooling the entire systems $=0.3 \mathrm{MW} \times 0.2=60 \mathrm{~kW}$. This corresponds to $\$ 36 \mathrm{k}$ per year. The total electrical cost per year is estimated at $\$ 773 k+113 k+36 k=\$ 922 \mathrm{k}$ per year. Adding $\$ 150 \mathrm{k}$ of labor to this results in an annual operating cost of $\$ 1072 \mathrm{k}$ per year or $\$ 126$ per hour. A $1 \mathrm{MW}$ system is capable of processing $100 \mathrm{~kg}$ of material per second at a dose rate of $10 \mathrm{kGy}$ if the beam is fully absorbed by the bio-solids. This translates into $\$$ 2.85 dollars per ton of materials processed at $10 \mathrm{kGy}$.

\section{Estimate of Accelerator Reliability}

The MWRD Stickney plant runs 24/7 each day for 365 days a year, so high average availability, redundancy, modular design, and ease of repair are all key design requirements. Recall, reliability, $R(t)$, is the frequency of failures over an interval of time. $R(t)=1-e-(t / M T F)$, where $t$ is the time at which the reliability is calculated and MTF is the mean time between failure, the inverse of which is the failure rate. For this analysis, we focus primarily on component failures that cause the beam from a module to stop requiring repair or maintenance action (e.g. RF power source, loss of cryogenic cooling, electron gun cathode failure, etc.). Such failures are counted as a hardware unavailability. We also anticipate shorter interruptions such as beam trips during operation, wherein it is possible to restart the beam within seconds or minutes. 
In the table below, we list the availability and the uptime of the accelerator. In addition, there is always extra capacity in the form of a $250-\mathrm{kW}$ accelerator module in stand-by for redundancy. In what follows: TBF is Mean Time Between Failures and MTTR is Mean Time To Repair.

\begin{tabular}{|c|c|c|c|c|}
\hline Component & MTBF (hr) & MTTR (hr) & $\begin{array}{l}\text { Availability (A=1- } \\
\text { MTTR/MTBF) }\end{array}$ & Downtime (hr) \\
\hline Cathode@ 0.025 A & 250,000 & 24 & $99.99 \%$ & $\begin{array}{l}52 \text { minutes } 34 \\
\text { seconds }\end{array}$ \\
\hline RF magnetron source & 8000 & 0.5 & $99.99 \%$ & $\begin{array}{l}52 \text { minutes } 34 \\
\text { seconds }\end{array}$ \\
\hline Cryocooler & 55000 & 8 & $99.98 \%$ & $\begin{array}{l}1 \text { hour } 45 \text { minutes } 7 \\
\text { seconds }\end{array}$ \\
\hline Vacuum & 100000 & 8 & $99.99 \%$ & $\begin{array}{l}52 \text { minutes } 34 \\
\text { seconds }\end{array}$ \\
\hline LLRF & 100000 & 6 & 99.99\% & $\begin{array}{l}52 \text { minutes } 34 \\
\text { seconds }\end{array}$ \\
\hline HV power supply & 30000 & 8 & $99.97 \%$ & $\begin{array}{l}2 \text { hours } 37 \text { minutes } \\
41 \text { seconds }\end{array}$ \\
\hline SRF cavity module & 80000 & 48 & $99.94 \%$ & $\begin{array}{l}5 \text { hours } 15 \text { minutes } \\
22 \text { seconds }\end{array}$ \\
\hline $\begin{array}{l}\text { Total availability of a } \\
250 \mathrm{~kW} \text { module (A) }\end{array}$ & & & $=99.85 \%$ & $\begin{array}{l}13 \text { hours } 8 \text { minutes } \\
24 \text { seconds }\end{array}$ \\
\hline $\begin{array}{l}\text { Accelerator availability } \\
\text { with four } 250 \mathrm{~kW} \\
\text { modules with one } \\
\text { spare }\end{array}$ & & & $99.99 \%$ & $\begin{array}{l}52 \text { minutes } 34 \\
\text { seconds }\end{array}$ \\
\hline $\begin{array}{l}\text { Accelerator availability } \\
\text { with four } 250 \mathrm{~kW} \\
\text { modules with NO } \\
\text { spare }\end{array}$ & & & $99.4 \%$ & $\begin{array}{l}\text { ( } 2 \text { days } 4 \text { hours } 33 \\
\text { minutes } 36 \text { seconds) }\end{array}$ \\
\hline
\end{tabular}

Table 9.1: Availability estimate for a $250 \mathrm{~kW}$ SRF accelerator module

If we have four modules running simultaneously with one spare module, the probability that the accelerator will be unavailable is when two of the five modules become unavailable. In general, if there are $\mathrm{n}$ modules, there are $\mathrm{n}$ ways that a single failure can occur. Given one fails, there are $(n-1)$ ways that a second module can fail. Removing double counting (all identical modules), we get $p=n(n-1) / 2$ ways that two systems can fails simultaneously. So, the probability that both fail $(F)$ is the product of each module's unavailability $(A)$ and the number of ways $(p)$. Therefore total acceleratory availability with 
four and one spare module, $A 5=1-F=1-\left[0.5^{*} n^{*}(n-1)^{*}(1-a)^{*}(1-a)\right]=99.99 \%$. If we use only the four accelerator modules with no spare then the availability A4 drops to $99.40 \%$ but saves a $20 \%$ of the cost. The availability requirement at MWRD and cost will dictate the choice of our final installation.

Based on commercially available information on cathode lifetimes, we estimate that by using a standard thermionic cathode (M-type cathode) at $0.25 \mathrm{~A}$ average current, the lifetime in our machine could be increased to $>250,000 \mathrm{hrs}$. The cryocooler that we currently use for our research has a mean-time-to-failure (MTF) of 40000-70000 hours, making all components positioned well for industrial application.

\section{Summary / Closing Remarks}

This report has summarized the conceptual design of a $1 \mathrm{MW}$ accelerator system that meets all FOA LAB 16-1438 requirements for a Type 3 accelerator and that we believe is fully viable for commercial irradiation of municipal bio-solids. Computer simulation indicates the beam physics works. Our simulation efforts have yielded no show-stoppers. We also believe we have developed a viable conceptual design for the accelerator that is ready to move to subsystem tests; a full engineering design; and construction of a first article $250 \mathrm{~kW}$ test accelerator. If such an accelerator were built, it would represent the first of a new class of cost effective, simple, SRF-based industrial accelerators that can enable many new accelerator applications. We have outlined key R\&D areas that require immediate funding support. We have also designed a beam delivery and shielding system that is viable for treating bio-solids from a large municipal waste water treatment facility such as the Stickney plant operated by MWRD.

Beyond the proposed R\&D, the next logical step is a full engineering design leading to the construction of the proposed test accelerator. 